\title{
Functions of frontostriatal systems in cognition: Comparative neuropsychopharmacological studies in rats, monkeys and humans
}

\author{
Y. Chudasama ${ }^{\mathrm{a}, *}$, T.W. Robbins ${ }^{\mathrm{b}}$ \\ ${ }^{a}$ Laboratory of Neuropsychology, National Institute of Mental Health, Convent Drive, Building 49, Room 1B80, Bethesda, MD 20892, USA \\ ${ }^{\mathrm{b}}$ Cambridge University, Department of Experimental Psychology, Downing Street, Cambridge CB2 3EB, UK
}

Accepted 31 December 2004

Available online 20 March 2006

\begin{abstract}
A comparative and integrated account is provided of the evidence that implicates frontostriatal systems in neurodegenerative and neuropsychiatric disorders. Specifically, we have made detailed comparisons of performance following basal ganglia disease such as Parkinson's disease, with other informative groups, including Alzheimer's disease, schizophrenia and attention deficit/hyperactivity disorder and structural damage to the frontal lobes themselves. We have reviewed several behavioural paradigms including spatial attention and set-shifting, working memory and decision-making tasks in which optimal performance requires the operation of several cognitive processes that can be successfully dissociated with suitable precision in experimental animals. The role of ascending neurotransmitter systems are analysed from the perspective of different interactions with the prefrontal cortex. In particular, the role of dopamine in attentional control and spatial working memory is surveyed with reference to its deleterious as well as facilitatory effects. Parallels are identified in humans receiving dopaminergic medication, and with monkeys and rats with frontal dopamine manipulations. The effects of serotonergic manipulations are also contrasted with frontal lobe deficits observed in both humans and animals. The main findings are that certain tests of frontal lobe function are very sensitive to several neurocognitive and neuropsychiatric disorders. However, the nature of some of these deficits often differs qualitatively from those produced by frontal lobe lesions, and animal models have been useful in defining various candidate neural systems thus enabling us to translate basic laboratory science to the clinic, as well as in the reverse direction.
\end{abstract}

Published by Elsevier B.V.

Keywords: Frontostriatal systems; Comparative neuropsychopharmacological studies; Neurocognitive; Neuropsychiatric; Executive function

\section{Introduction}

The frontal cortex mediates those cognitive functions, usually referred to as executive, that are needed to optimise performance in complex tasks and include a number of psychological processes, namely: (1) selection and perception of pertinent information; (2) maintenance, retrieval and manipulation of information held 'on-line' in working memory;

Abbreviations: GPi, internal segment of globus pallidus; $\mathrm{SNr}$, substantia nigra pars reticulata; VP, ventral pallidum; MD, medialis dorsalis; MDpc, medialis dorsalis pars parvocellularis; MDmc, medialis dorsalis pars magnocellularis; VAmc, ventralis anterior pars magnocellularis; VApc, ventralis anterior pars parvocellularis; VLo, ventralis lateralis pars oralis; VLm, ventralis lateralis pars medialis; cl, caudolateral; ldm, lateral dorsalmedial; mdm, medial dorsomedial; pm, posteromedial; rd, rostrodorsal; rl, rostrolateral; rm, rostromedial

* Corresponding author. Tel.: +1 301496 5625x235; fax: +1 3014020046.

E-mail address: Yogita@ln.nimh.nih.gov (Y. Chudasama).
(3) self-directed planning and organisation in relation to specific contingencies; (4) behavioural control and adaptation to changes in the environment; and (5) appropriate decisionmaking on the basis of positive and negative outcomes. A disruption of cognitive function often results in a heterogeneous pattern of deficits including distractibility and perseveration, social irresponsibility, lack of initiative, impulsivity and profound disinhibition. These cognitive symptoms are characteristic of many neurodegenerative disorders such as Alzheimer's and Parkinson's disease, psychiatric illness including schizophrenia, depression and obsessive compulsive disorder (OCD), as well as pervasive developmental disorders such as attention-deficit hyperactivity disorder (ADHD).

It is now apparent that cognitive-executive functions are mediated by independent and interacting neural systems that may be compromised by different forms of pathology, leading to a range of cognitive profiles. The frontostriatal network is particularly relevant because its dysfunction results in a pattern of deficits that distinguishes the basal ganglia diseases 


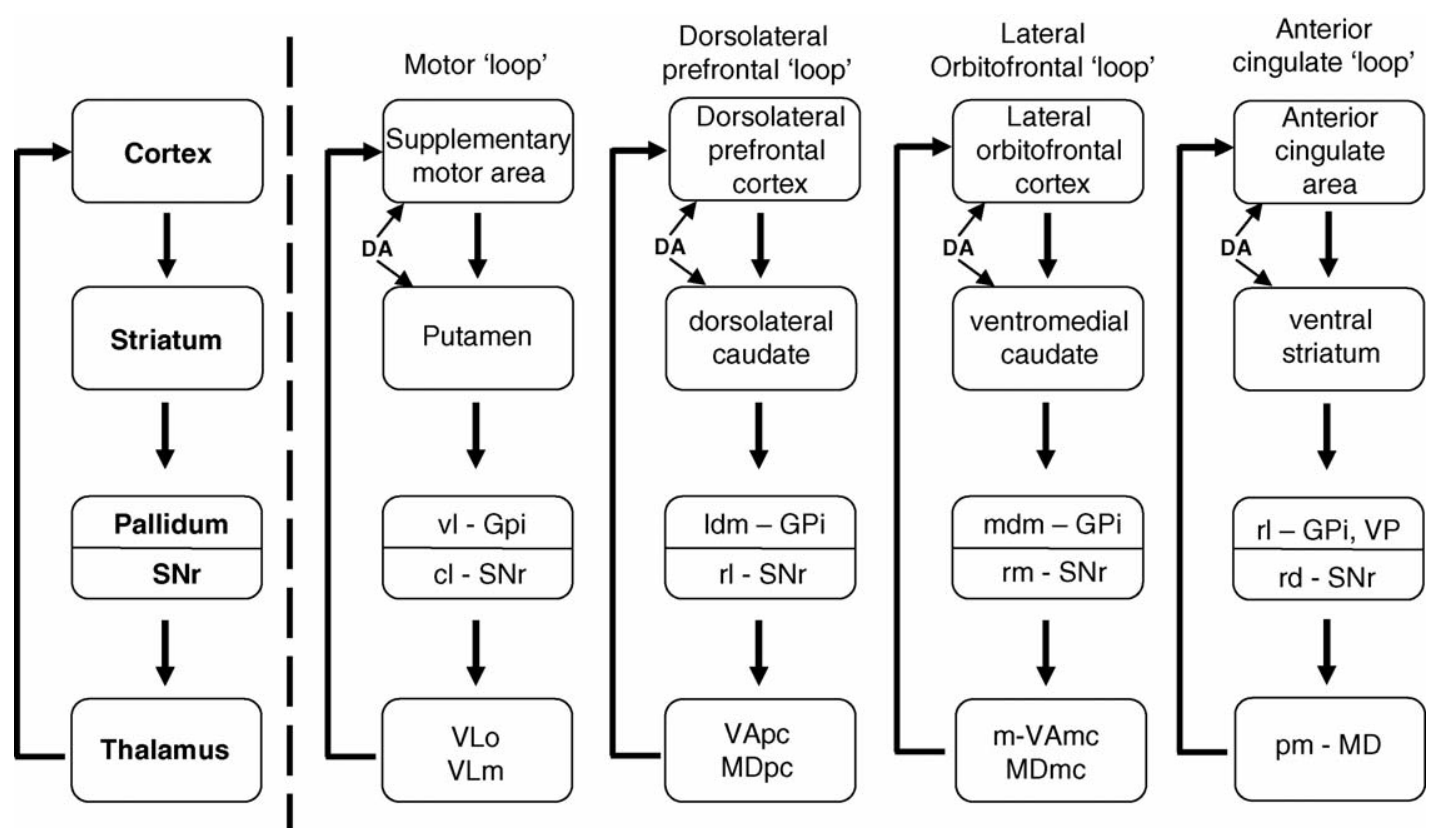

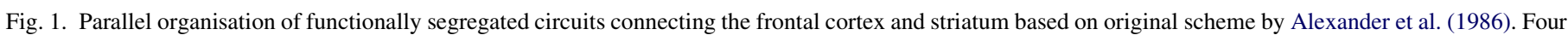

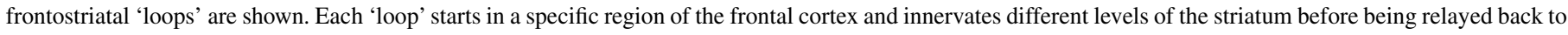

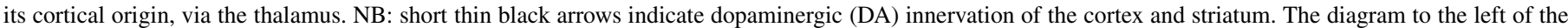
dashed line indicates the general organisation of the cortico-striatal-pallidal-thalamic loop.

(e.g. Parkinson's and Huntington's disease) from dementia of the Alzheimer's type which typically comprises disruption, at least in the early stages, to the medial temporal lobe regions. These findings coincide with the anatomical and structural organisation of corticostriatal 'loops' (Alexander et al., 1986) largely derived from anatomical and electrophysiological studies in non-human primates, which involves the parallel processing of descending cortical information that is relayed back to the cortex via the thalamus (see Fig. 1). The parallel organisation of these circuits has proved useful in clarifying not only normal functions of the basal ganglia, but also in efforts to understand the behavioural disturbances that occur in basal ganglia disorders. To the extent that this framework is an accurate representation of functional organisation in the normal brain, it can be used successfully to implicate pathological mechanisms, including dysfunctional neurochemical systems (e.g. dopamine), which may account for the clinical manifestation of basal ganglia disorders.

Significant advances in neuroanatomy have further refined the descriptions of the frontostriatal circuits and their interaction with other complex, cortical-subcortical circuits relevant to behaviour, such as the visual association regions of the temporal cortex (Middleton and Strick, 1996), the hippocampus (Goldman-Rakic, 1987) and the amygdala (Kelley et al., 1982). Together with the increasing sophistication of neuropsychological assessment, advances in molecular pharmacology, and highly developed imaging techniques for studying physiological correlates of activity in the human brain, there has been much progress in understanding the frontostriatal contribution to the nature and extent of cognitive deficits that may underlie some of the behavioural symptoms observed in disorders of brain and behaviour. Nonetheless, animal studies in the neurobiology of cognition provide some necessary inherent advantages over human studies. In addition to large individual differences in intelligence, education, health and experience, a more serious difficulty with human patients is to determine the relevance of individual neuropathological deficits (i.e. brain structures, neurotransmitter systems) to distinct features of the functional deficit (i.e. behaviour). For example, although it is accepted that there exists a well defined profile of intellectual impairment in Parkinson's disease (PD) that is related to the primary pathology of the nigro-striatal dopamine pathway, it is difficult to disentangle the contribution of additional factors such as degeneration of the basal forebrain or locus ceruleus or indeed cortical Lewy bodies that may also play a role in the overall cognitive deficit syndrome. Furthermore, the role of medication, such as L-Dopa, may also contribute to the cognitive impairment.

Our own approach has been to compare cognitive performance of brain damaged human patients with animal models of their disorder, using tasks that can be theoretically decomposed into their constituent cognitive elements (see Table 1). Thus, one major advantage of animal studies is that we can reproduce in experimental animals particular features of the neuropathological and neurochemical changes observed in humans and establish their consequences. The major disadvantage however, is the difficulty of relating the behavioural deficit in animals to cognitive deficits in humans. For example, planning deficits in humans entail some level of evaluation and the effective sequence of mental responses relative to specific goals; cognitive processes which can be difficult to model in animals. However, the elements of planning which constitute a working memory load, the capacity to sequence responses, to shift on the basis of rewarding and punishing feedback, and 
Table 1

Comparable tests of cognition in rats, monkeys and humans

\begin{tabular}{|c|c|c|c|}
\hline Cognitive process & Species & Cognitive test & References \\
\hline \multirow{3}{*}{$\begin{array}{l}\text { Visuospatial } \\
\text { attention/sustained } \\
\text { attention }\end{array}$} & Rats & 5 choice serial reaction time task & $\begin{array}{l}\text { Carli et al. (1983), Muir et al. (1996), Granon et al. (2000), } \\
\text { Chudasama et al. (2003a) }\end{array}$ \\
\hline & Monkeys & $\begin{array}{l}5 \text { choice serial reaction time task; } \\
\text { reaction time task }\end{array}$ & Weed et al. (1999), Spinelli et al. (2004) \\
\hline & Humans & Continuous performance test & $\begin{array}{l}\text { Rosvold et al. (1956), Orzack and Kornetsky (1966), } \\
\text { Sahakian et al. (1993), Jones et al. (1995) }\end{array}$ \\
\hline \multirow[t]{3}{*}{$\begin{array}{l}\text { Spatial working } \\
\text { memory }\end{array}$} & Rats & Delayed alternation & $\begin{array}{l}\text { Olton (1982), Dunnett (1985, 1993), Zahrt et al. (1997), Floresco } \\
\text { and Phillips (2001), Chudasama and Robbins (2004b), Chudasama et al. (2004c) }\end{array}$ \\
\hline & Monkeys & $\begin{array}{l}\text { Spatial delayed response; } \\
\text { self-ordered working memory }\end{array}$ & $\begin{array}{l}\text { Rosvold et al. (1961), Brozoski et al. (1979), Arnsten et al. (1994), } \\
\text { Passingham (1985), Sawaguchi and Goldman-Rakic (1991), Collins et al. (1998) }\end{array}$ \\
\hline & Humans & Subject-ordered working memory & $\begin{array}{l}\text { Petrides and Milner (1982), Owen et al. (1990, 1996), } \\
\text { Sahakian et al. (1990), Diamond et al. (1997), Mehta et al. (2004a, 2004b) }\end{array}$ \\
\hline \multirow[t]{3}{*}{$\begin{array}{l}\text { Set-shifting } \\
\text { and reversal }\end{array}$} & Rats & $\begin{array}{l}\text { Attentional set-shifting; } \\
\text { discrimination and reversal learning }\end{array}$ & $\begin{array}{l}\text { Bussey et al. (1994), Birrell and Brown (2000), Barense et al. (2002), } \\
\text { Chudasama and Robbins (2003) }\end{array}$ \\
\hline & Monkeys & $\begin{array}{l}\text { Intra- and extra-dimensional (ED/ID) } \\
\text { set-shifting; discrimination and } \\
\text { reversal learning }\end{array}$ & $\begin{array}{l}\text { Roberts et al. (1994), Dias et al. (1996), Collins et al. (2000), } \\
\text { Crofts et al. (2001) }\end{array}$ \\
\hline & Humans & $\begin{array}{l}\text { WCST; intra- and extra-dimensional } \\
\text { (ED/ID) set-shifting; discrimination } \\
\text { and reversal learning }\end{array}$ & $\begin{array}{l}\text { Milner (1963), Downes et al. (1989), Owen et al. (1992), } \\
\text { Swainson et al. (2000), Pantelis et al. (2004), McLean et al. (2004), } \\
\text { Cools et al. (2001a, 2001b) }\end{array}$ \\
\hline \multirow[t]{3}{*}{$\begin{array}{l}\text { Decision-making } \\
\text { and impulsivity }\end{array}$} & Rats & $\begin{array}{l}\text { Delayed reward; temporal discounting; } \\
\text { stop-signal task }\end{array}$ & $\begin{array}{l}\text { Mazur (1987), Richards et al. (1999), Mobini et al. (2000), } \\
\text { Cardinal et al. (2001), Winstanley et al. (2004a, 2004b) }\end{array}$ \\
\hline & Monkeys & Go/No-go task; stop-signal task & $\begin{array}{l}\text { Pribram and Mishkin (1955), Iversen and Mishkin (1970), } \\
\text { Petrides (1986), Schall et al. (2002) }\end{array}$ \\
\hline & Humans & $\begin{array}{l}\text { Iowa gambling task; } \\
\text { Cambridge Gamble Task }\end{array}$ & $\begin{array}{l}\text { Damasio (1994), Bechara et al. (1994), Rahman et al. (1999), } \\
\text { Rogers et al. (1999b, 1999c), Manes et al. (2002), Clark et al. (2003) }\end{array}$ \\
\hline
\end{tabular}

Note: Some references in Table 1 may not be cited in the main text.

respond according to conditional rules can be readily addressed by primate and rodent neuropsychological studies and are included in our own battery of tests for monkeys and humans (i.e. CANTAB; Cambridge Neuropsychological Test Automated Battery). Although several cognitive tests used with humans has been derived from animal cognitive learning theory, such as the delayed-matching tests of recognition memory, in some cases, the cross-species comparison has been made in the opposite direction whereby a human neuropsychological test, the WSCT (Wisconsin Card Sorting Test), was made more accessible for use with monkeys, specifically by turning it into a series of simpler tests that decomposed its elementary cognitive constituents. Of course, this approach facilitates our understanding of the nature of the deficit in humans because it enables us to report with specificity, the precise difficulty an individual patient might have with the requirement of that particular task.

In addition to isolating the neural substrates of cognitive deficits in clinical patients, is the evidence that disorders of brain and behaviour include neurochemical pathology of the modulatory catecholaminergic (dopamine, serotonin and noradrenalin) and cholinergic neurotransmitters, also known to play an important role in cognitive functions. This evidence is derived from experimental studies in animals that have made relatively selective lesions of these projection pathways and have reported deficits in a variety of cognitive tasks (e.g. Brozoski et al., 1979). Furthermore, the main effect of drug therapy such as Ritalin, neuroleptics or selective serotonin reuptake inhibitors (SSRIs), is to alter the activity of the modulatory systems so as to bring about cognitive improvement. Nevertheless, the degree of overlap of dysfunctional neuropathological and neurochemical systems has implicated abnormalities in frontostriatal circuitry in virtually all neurological and neuropsychiatric disorders and thus animal models provide important experimental tools for understanding the mechanisms of drug action, as well as the development and screening of appropriate treatments for the alleviation of symptoms arising from brain disorders such as dementia and psychiatric illness.

\section{Modeling attentional dysfunction}

There is considerable evidence that changes in attention can influence a number of cognitive processes such as awareness of signals and objects as in disorders of neglect and selection, and interpretation of incoming signals as in schizophrenia. Advances in the neurobiology of animal behaviour have made it possible strategically to apply theoretical notions of attention such as selection, vigilance and control, formally derived from paradigms used in cognitive psychology to experimental animals including the mouse and rat. However, studies in experimental animals have been biased towards understanding the syndrome of sensorimotor neglect that commonly occurs following unilateral striatal-dopamine lesions (Ungerstedt, 1971; Marshall and Teitelbaum, 1977; Annett et al., 1992) using covert orienting paradigms (e.g. Posner, 1980; Bowman 
et al., 1993; Ward and Brown, 1997) in which typically the animal is required to hold its head in a specific location while peripheral target stimuli are presented. Thus, observed deficits in animals with unilateral striatal lesions on these types of tasks were considered failures in organising orienting responses, although it was not immediately clear from the results if these deficits were compromised by impairments in response control given the long history of the role of the striatum in the cognitive control over action (Reading et al., 1991; McDonald and White, 1993; Mink, 1996). Indeed, from our own analysis, it became increasingly apparent that striatal neglect was more likely a response-related deficit, rather than a pure attentional one (Carli et al., 1985, 1989; Brasted et al., 1999; Brown and Robbins, 1989).

Nonetheless, attentional deficits form a prominent part of the cognitive profile associated with many psychiatric disorders that are typically characterised using tests of frontal lobe function such as shifting functions that are engaged in the WCST, and sustained attentional demands in the continuous performance test (CPT). Originally derived from research in human experimental psychology and included in CANTAB, attentional shifting, which will be discussed in a later section, and continuous performance can now both successfully be applied to experimental animals including rats and monkeys (Roberts et al., 1994; Chudasama and Robbins, 2004a; Brown and Bowman, 2002). These functions have important translational properties in view of the assumption that experimental animals have the basic building blocks of cognition that are seen in complex cognitive capabilities in humans. In this section, we will show that many attentional symptoms in humans can be modelled by simpler versions of what are considered to be human analogues in experimental animals (see Robbins, 1998).

\subsection{Choice serial reaction time task}

An example of an animal test that has translational properties is the five choice serial reaction time task (5CSRTT; Carli et al., 1983) that was modelled after its human analogue, the continuous performance test (CPT; Rosvold et al., 1956; Wilkinson, 1963) and has been shown to recruit several attentional operations that depend on specific neural networks. Formally devised for assessing generalised brain damage (Rosvold et al., 1956), the CPT is considered a sensitive measure of attention; patients with right frontal lobe damage show long reaction times and miss more targets relative to controls (Rueckert and Grafman, 1996), and Berman and Weinberger (1990) showed greater activation in the right frontal cortex during performance of CPT compared with other 'frontal' prototypical tasks such as the WCST. In addition, the CPT has been used to assess attention in several clinical groups including patients with schizophrenia who typically show a reduction in performance over time when required to continuously monitor infrequent and unpredictable targets (e.g. letters). Although it is thought that impaired performance in the CPT is indicative of a vigilance decrement (Parasuraman and Davis, 1977), the precise nature of the attentional deficit in schizophrenia has been difficult to resolve (Davis and Parasuraman, 1982; Nestor and O'Donnell, 1998). In the paradigm used for rats however, different forms of attention can be readily investigated and dissociated following selective neuroanatomical or neurochemical manipulations, thus a neural system that is presumably pathological in schizophrenia may be different from the neural system that is compromised in, for example, ADHD.

In rats, the 5CSRTT is conducted in an automated operant chamber equipped with five exposed apertures located opposite a food magazine. The rat is required to sustain and divide its attention across five spatial locations in order to detect a brief visual light target that occurs randomly in one of the five locations. As well as measuring accurate target detection (response accuracy), the 5CSRTT allows us to measure different mechanisms of behavioural inhibition such as premature 'impulsive' responses related to response preparation, as well as 'compulsive' perseverative responses that may occlude the animals' ability to monitor ongoing behaviour. Finally, measures of latency provide some overall assessment of motor and motivational status and even decision time, depending on the overall profile of results (for detailed description of apparatus, training protocol and behavioural profiles, see Carli et al., 1983; Robbins et al., 1993; Robbins, 2002).

The effect of large medial prefrontal (mPFC) lesions on the 5CSRTT performance is profound (Muir et al., 1996); rats show inaccurate target detection, they are highly perseverative, and are slow responders. Recent studies have refined the lesions to discrete regions of the prefrontal cortex which has helped define the complementary roles of the different frontal sectors (Passetti et al., 2002; Chudasama et al., 2003a; see Table 2). For example, damage to dorsal mPFC leads to impairments in discriminative accuracy whereas lesions to the more ventral $\mathrm{mPFC}$ regions promote impulsivity, and damage to the orbitofrontal cortex (OFC) causes perseveration (Chudasama et al., 2003a). Clearly, the rodent frontal cortex has a complex role in integrating aspects of attention and behavioural inhibition in order to optimise performance in the 5CSRTT. The diversity of the behavioural effects following selective frontal lesions is consistent with the scheme of partially segregated frontostriatal 'loops' (Alexander et al., 1986); different frontal regions project to different sectors of the striatum. Hence, the lateral striatum (LS) receives its projections from the lateral frontal and sensorimotor regions of the neocortex (Donoghue and Herkenham, 1986; McGeorge and Faull, 1989), whereas the medial striatum (MS) is innervated by the medial prefrontal cortex (Divac and Diemer, 1980; McGeorge and Faull, 1989; Sesack et al., 1989), but it is only the medial portion of the striatum that is implicated in cognitive function (e.g. Dunnett, 1990; Eagle et al., 1999). Thus, similar to large mPFC lesions, MS lesions produce longlasting deficits in several aspects of 5CSRTT performance including diminished response accuracy and increased premature and perseverative responding (Rogers et al., 2001; see Table 2) that is probably monitored by different regions of the mPFC (Chudasama et al., 2003a). Similar results are also 
Table 2

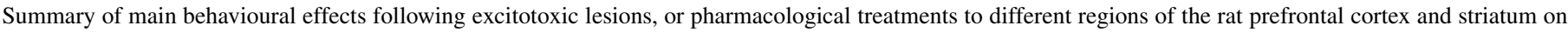
performance of the 5CSRTT

\begin{tabular}{|c|c|c|c|c|c|c|}
\hline & \multicolumn{3}{|c|}{$\begin{array}{l}\text { Different regions of the } \\
\text { frontal cortex }\end{array}$} & \multicolumn{3}{|c|}{$\begin{array}{c}\text { Different regions of the } \\
\text { striatum }\end{array}$} \\
\hline & $\begin{array}{l}\text { Dorso- } \\
\text { medial }\end{array}$ & Ventral & Lateral & $\begin{array}{l}\text { Dorso- } \\
\text { medial }\end{array}$ & Ventral & Lateral \\
\hline $\begin{array}{l}\text { Accuracy } \\
\text { 'attention' }\end{array}$ & 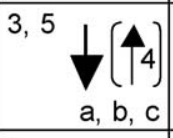 & & & $\mathrm{d}, \mathrm{e}$ & & \\
\hline $\begin{array}{l}\text { Premature } \\
\text { 'impulsive' }\end{array}$ & $1 \quad 4(\mid 2)$ & 1 & & $\mathrm{~d}, \mathrm{e}$ & 6 & \\
\hline $\begin{array}{l}\text { Perseverative } \\
\text { 'compulsive' }\end{array}$ & $c, g$ & & & $\mathrm{~d}, \mathrm{e}$ & & \\
\hline $\begin{array}{c}\text { Latency } \\
\text { 'decision speed' }\end{array}$ & $\begin{array}{c}\mathrm{T} \\
\mathrm{a}, \mathrm{b}, \mathrm{c}\end{array}$ & & $\Delta$ & d & & $\Lambda$ \\
\hline
\end{tabular}

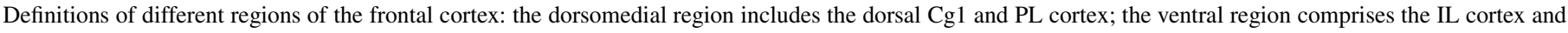
OFC that includes ventromedial and ventrolateral orbitofrontal sectors; the lateral frontal cortex includes motor areas (M1 and M2).

Key to effects relative to sham or baseline: $\mathbf{A}$, increase; $\downarrow \downarrow$, decrease; $\_$, no change.

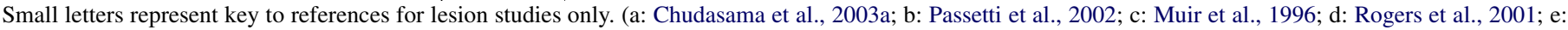
Christakou et al., 2001; f: Christakou et al., 2004; g: Chudasama and Muir, 2001).

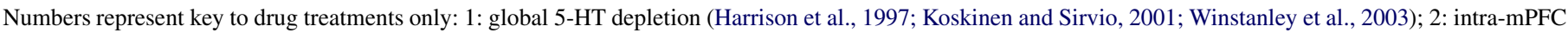

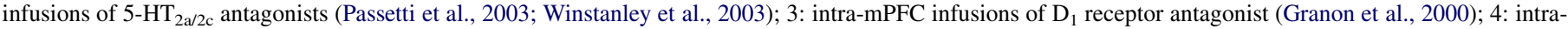

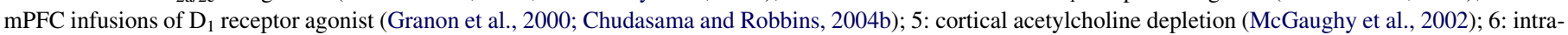
accumbens infusion of d-amphetamine (Cole and Robbins, 1989); 7: DA depletion from dorsolateral striatum (Baunez and Robbins, 1999).

obtained using the more direct approach of disconnecting the mPFC-dorsomedial striatum communication (Christakou et al., 2001). By comparison, lesions of the lateral striatum produce a very different pattern of deficits in the 5CSRTT, namely increased omissions and retarded learning (Rogers et al., 2001) that is reminiscent of the latency deficit observed after lesions of the lateral frontal cortex (Muir et al., 1996). Of course, some of these deficits may well be due to damage to structures of striatal outflow such as the subthalamic nucleus (Baunez and Robbins, 1997) the function of which is also critically dependent on the frontal cortex (Chudasama et al., 2003b). Finally, lesions made to the ventral striatum (VS) subsuming the nucleus accumbens (Nac) produce a compulsive tendency of perseverative responding that is specifically related to the inability to successfully integrate behaviour according to the reward schedule of the task (Christakou et al., 2004). Together, these findings are useful in understanding how 'intact' prefrontal cortico-striatal systems may function to integrate complex behaviours such as the selection and suppression of planned response sequences; this behavioural syndrome of dysexecutive control is evident in a variety of disorders in which the frontal cortex is seriously implicated such as patients with dementia or psychiatric disturbances of schizophrenia and ADHD.

Psychopharmacological studies that have focused on selective neurochemical manipulations of the ascending monoaminergic and cholinergic systems within the PFC and related structures, has enabled us to show dissociations in the way in which the PFC may modulate different aspects of discrimination and control (Robbins and Everitt, 1995). For example, manipulations of serotonin $(5-\mathrm{HT})$ produce a pattern of behaviour in the 5CSRTT suggestive of its likely interactions with the DA system (Meltzer, 1989). Thus, global 5-HT depletion markedly increases impulsive responses (Harrison et al., 1997; Koskinen and Sirvio, 2001; Winstanley et al., 2003) mimicking the effects of d-amphetamine when directly infused into the Nac (Cole and Robbins, 1989). In addition, in-vivo microdialysis studies that can sample changes in neurotransmitters and their metabolites engaged during task performance, have revealed that cortical DA is particularly engaged during 5CSRTT task performance, whereas 5-HT correlates with the performance of impulsive responses (Dalley et al., 2002) suggesting that variations in 5-HT levels may help distinguish impulsive characteristics from attentional ones.

There is evidence, however, that the DA mediated functions within the ventral striatum are regulated by glutamatergic afferents from the PFC (Gariano and Groves, 1988; Jaskiw et al., 1990; Murase et al., 1993; Taber and Fibiger, 1995). Thus, electrical stimulation of the PFC (Taber and Fibiger, 1995) or local application of glutamate (Moghaddam et al., 1990) increases extracellular levels of DA in the striatum, and 
Dalley et al. (1999) has reported that lesions of the PFC produce alterations in CREB (cAMP response element binding protein) phosphorylation in the Nac following d-amphetamine treatment. These findings are particularly relevant to altered mesocorticolimbic DA transmission produced by prolonged or intermittent exposure to stimulant drugs (e.g. methylphenidate or amphetamine); the behavioural deficits of inattention and impulsivity appear to be strikingly similar to the core deficits in ADHD.

These neurochemical observations are consistent with other pharmacological approaches such as microinfusions of selective DA receptor agents directly into the $\mathrm{mPFC}$; these findings have been useful in modeling patterns of behaviour that appear to adjust via dopaminergic mechanisms depending on overall control levels of performance. Thus, while $\mathrm{D}_{1}$ receptor agonists infused directly into the $\mathrm{mPFC}$ enhance accuracy in low performing animals, $D_{1}$ receptor antagonists impair performance when it is relatively high (Granon et al., 2000). Furthermore, enhancing attentional arousal using mPFC $\mathrm{D}_{1}$ stimulation can have a subsequent modulatory effect on memory performance by either impairing it when it is 'high,' and improving it when it is 'low' (Chudasama and Robbins, 2004b). These findings have implications for human clinical conditions such as ADHD where psychostimulant therapy, such as Ritalin (methylyphenidate), has beneficial effects on patients that are essentially already 'stimulated.'

Unlike the effect of DA $D_{1}$ agents, the infusion of the $D_{2}$ receptor agent, sulpiride, was without effect in the 5CSRTT, but remarkably ameliorated an accuracy deficit in animals with mPFC lesions when administered systemically (Passetti et al., 2003). This effect may possibly reflect a striatal mode of action caused hypothetically by over-activity of sub-cortical DA that may have contributed to the lesion induced disruption of performance. Although intra-mPFC infusions of DA receptor agents had little or no effects on other response measures such as premature or perseverative responding, there is evidence that changes in DA levels caused by, for example, amphetamine, produce a syndrome of stereotyped behaviour that is mediated by DA release in the dorsal striatum (e.g. Creese and Iversen, 1975; for review see, Robbins et al., 1990) and this may be related to many of the psychotic symptoms thought to be precipitated following amphetamine abuse in schizophrenia (Connell, 1958; Snyder, 1973), which is significant for this group of patients compared with patients with dementia.

Observations following manipulations to the cholinergic system have also been useful in predicting patterns of attentional dysfunction and subsequent effects of pro-cognitive drugs used with patients. Thus, acetylcholine depletion in the PFC caused by basal forebrain lesions, produces accuracy deficits in the 5CSRTT together with disinhibitory deficits, particularly when engaging sustained attentional mechanisms in high attention demanding conditions (McGaughy et al., 2002). While anti-muscarinic agents such as scopolamine aggravate these effects, they can be ameliorated by procholinergic drugs such as physostigmine or nicotine (Muir et al., 1995). However, the modulatory role of acetylcholine in cognitive function is particularly interesting given its role in maintaining working memory, as well as serving to optimise attentional processing (Chudasama et al., 2004c). These findings are relevant to the attention enhancing action of pro-cholinergic drugs used with patients with Alzheimer's disease known to be deficient in cholinergic markers performing a CANTAB version of the human 5CSRTT (Sahakian et al., 1993) and their deteriorating performance in the learning of several forms of material and short-term memory function (Sahakian et al., 1990).

Hence, the 5CSRTT has proven to be useful for analysing the functions of the different neurotransmitters in the rodent brain, and their interactions with each other which need to be considered when predicting their impact on performance. Although currently, there are no primate studies that have directly examined the effects of frontal or striatal manipulations during CPT performance, there now exist versions of the 5CSRTT for use with rhesus monkeys (Weed et al., 1999) marmosets (Spinelli et al., 2004), as well as mice (Humby et al., 1999) which will hopefully enable integrative crossspecies comparisons to be made. But attentional deficits form only part of the impaired cognitive profile in human clinical conditions. For example, certain tasks used to index working memory in experimental animals such as spatial delayed response, are functionally related to the 5CSRTT paradigm in that the animal is required not only to detect a visual target in space but also to remember its location over a short delay (see Chudasama and Robbins, 2004b). Moreover, 5CSRTT performance also requires other 'building blocks' of cognitive function, such as the capacity to initiate responses but to prevent impulsive behaviours, but also repeated, maladaptive perseveration. These mechanisms of executive control also contribute to the overall temporal scheduling, or planning, of behaviour from trial to trial. We therefore consider these more complex processes in the context of other tests of the 'CANTAB' battery.

\section{CANTAB (Cambridge Neuropsychological Test Automated Battery)}

CANTAB was originally devised for the assessment of cognitive function in elderly and dementing patients (Robbins et al., 1994). It is a battery of computerised tests administered with the aid of a touch-sensitive monitor. Its guiding principle was two-fold: (1) to design tests in which could be broken down into their constituent cognitive components in order to define which aspect of cognition was impaired and which was spared that was relevant to performance for that particular task; and (2) the tasks could be performed by monkeys, as well as humans using the same basic hardware and software so that the perceptual processing required to perform the task is likely to be similar across species. The battery has now been used extensively in the testing of patients with $\mathrm{AD}$ and other forms of dementia (Sahakian et al., 1988, 1990), basal ganglia disorders including PD (Downes et al., 1989; Owen et al., 1992, 1993), Korsakoff's syndrome (Joyce and Robbins, 1991), depression (Abas et al., 1990; Swainson et al., 2001), schizophrenia (Elliott et al., 1995) as well as children with learning difficulties or 
autism (Hughes et al., 1994). The main rationale of CANTAB is to seek illuminating functional dissociations of executive and non-executive mechanisms, via comparative studies of brain damaged humans and monkeys and results have indicated that some of the tests are sensitive to frontal or temporal lobe dysfunction. In this way, CANTAB has been very useful in accurately distinguishing, for example, AD patients from depressed patients (Swainson et al., 2001) thus providing a potential means of early diagnosis. Ultimately, the observed deficits can be related to studies with animals with neuronal and neurochemical abnormalities produced by the disease process to get a better idea of how to target the deficit by pharmacological means.

Although several tasks constitute the CANTAB test battery, for the purpose of this review, we will focus on three main CANTAB tests: extra- and intra-dimensional attentional set shifting (ED/ID), self-ordered spatial working memory, and the Cambridge Gamble Task.

\section{Modeling the WCST: extra- and intra-dimensional attentional set-shifting}

An example of a paradigm that has been made useful for both human and monkeys in detecting different executive impairments is the extra-dimensional shift (EDS; Slamecka, 1968; Downes et al., 1989; Roberts et al., 1994). In EDS the subject is first trained to respond to one stimulus dimension (e.g. lines or shapes) of a complex, multidimensional compound stimulus and is then required to respond instead to a previously irrelevant dimension. The critical comparison is when the subject is required to make an intra-dimensional shift (IDS) which requires the ability to transfer responses to novel exemplars within the same stimulus dimension thus requiring the establishment of an 'attentional-set.' In addition, reversals (when the reward contingencies of the relevant dimension are reversed), can be introduced at both EDS and IDS stages in order to assess control over behaviour by the dimension rather than by a specific exemplar of it (for detailed description and experimental protocol, see Roberts and Sahakian, 1993; Roberts et al., 1994). The salient features of the ED/ID setshifting test are: (1) it constitutes the main requirement in the WCST, the primary clinical index for frontal lobe dysfunction (Milner, 1963); (2) it allows the separation of two levels of cognitive flexibility; perseveration to a specific exemplar or a stimulus dimension, as well as attentional set-shifting; processes which constitute the complexity of the WCST; and (3) a parallel version has been devised for testing monkeys (Roberts et al., 1988), thus providing significant advantages for understanding the neural and neurochemical nature of the deficits in humans, as well as in experimental animals. It is particularly relevant, therefore, that disorders of neurocognitive decline and neuropsychiatric illness such as schizophrenia and ADHD, all show deficits in set shifting ability (Owen et al., 1992; Pantelis et al., 2004; McLean et al., 2004), and all show some disturbance of frontostriatal neural networks (Rogers et al., 2000; Liddle et al., 1992; Castellanos et al., 1994; Castellanos, 1996).

\subsection{Clinical and neuropsychological findings}

The ability to perform the various stages of ED/ID set shifting and reversal learning appears to be mediated by selective prefrontal regions and associated subcortical structures. Studies using primates with excitotoxic fibre-sparing localised lesions of different regions of the PFC indicate that dorsolateral prefrontal cortex (DLPFC) mediates EDS, while reversal learning is associated with the more ventral OFC (Dias et al., 1996). This analysis is consistent with results from a recent neuroimaging study in humans in which shifting an attentional set activated the DLPFC and putamen, whereas only reversal learning which involved switching between two exemplars of the same dimension, differentially activated the ventral caudate nucleus/ventral striatum (Rogers et al., 2000). Together, these data are important in demonstrating that setshifting ability is dependent on ventral orbitofrontal as well as dorsolateral regions via parallel segregated frontostriatal circuits (Alexander et al., 1986) and task performance may well be compromised by striatal pathology, which occurs relatively early in basal ganglia disorders, and may therefore disrupt function of these neural loops.

One of the most valuable features of ED/ID testing is that not only is it validated as being sensitive to frontal lobe damage, but it is also the only 'frontal' test that is sensitive to the early stages of PD; unmedicated and early stage PD patients exhibit a specific deficit at the EDS stage because they are unable to form and maintain an attentional set (Downes et al., 1989; Owen et al., 1992). However, unlike early PD patients, clinically asymptomatic HD patients are impaired at shifting attentional set at the EDS stage, whereas patients with advanced HD exhibit a dramatic increase in perseverative responding at the simple reversal stage, preventing them from even reaching the EDS stage (Lange et al., 1995). These observations are similar in some ways to patients with frontotemporal dementia (FTD) who have more selective ventral OFC pathology and show much greater deficits on reversals rather than the EDS stage (Rahman et al., 1999). This suggests therefore, that 'shifting,' which has been associated with the DLPFC, and 'reversal learning,' thought to be sensitive to medial orbital damage (Dias et al., 1996) are distinct operations which express according to the stage of the disease process, presumably as a result of how $\mathrm{HD}$ affects the striatal sectors that receive differential projections from these prefrontal areas (Lawrence et al., 1998a). Thus, this comparison of deficits that occur either early or late in the course of the illness is consistent with the dorsal-to-ventral progression of the neuropathology in the striatum (Hedreen and Folstein, 1995; Lawrence et al., 1998a).

Specific impairments in the ability to perform the ID shift have also been identified in advanced stages of certain illnesses (see Table 3) although the neural correlate of IDS performance have not yet definitively been identified. Nonetheless, an apparent progression of deficit has been observed in crosssectional studies of patients with schizophrenia; well preserved high functioning schizophrenic patients show deficits at the EDS stage (Elliott et al., 1995, 1998), whereas increased severity of the illness is associated with impaired performance 
Table 3

Impaired performance on EDS, IDS set-shifting and reversal learning paradigm: comparison of clinical groups and candidate neural systems

\begin{tabular}{|c|c|c|}
\hline EDS & IDS & Reversal \\
\hline Dorsolateral prefrontal lesions & Neural substrate unknown & Orbitofrontal lesions \\
\hline High functioning schizophrenics & Low functioning schizophrenics & Low functioning schizophrenics \\
\hline Early/unmedicated Parkinson's disease & Advanced Parkinson's disease & Advanced Parkinson's disease \\
\hline Attention-deficit hyperactivity disorder & Frontotemporal dementia & Frontotemporal dementia \\
\hline Chronic amphetamine abusers & Chronic heroin abusers & Low serotonin (Normals) \\
\hline Preclinical Huntington's disease & Low prefrontal Dopamine & Advanced Huntington's disease \\
\hline Obsessive-compulsive disorder ${ }^{\mathrm{a}}$ & & Cortical cholinergic depletion \\
\hline
\end{tabular}

${ }^{\mathrm{a}}$ Watkins et al. (2005).

at the IDS stage (Pantelis et al., 1999, 2004). Importantly, these deficits in set stability are not merely functions of test sensitivity or global cognitive impairment. For example, patients early in the course of $\mathrm{AD}$ can perform set shifting as well as controls despite a major deficit in short-term memory (Sahakian et al., 1990) and patients with damage to the temporal cortex or have amygdala-hippocampectomies are unimpaired on ED/ID testing (Owen et al., 1991). Clearly, the clinical relevance of the ED/ID test is that it is more specifically a test of anterior cortical function including the frontostriatal circuitry rather than a test of posterior cortical deficits, involving, for example the temporal lobe.

\subsection{Effects of medication}

In human neuropsychological testing, an important factor is the effect of medication on behavioural performance. For example, DA-ergic drugs such as levodopa (L-Dopa) are efficacious in the treatment of motor symptoms of PD (e.g. Yahr, 1990; Growdon et al., 1998) and controlled withdrawal of the L-Dopa in PD patients produces a generalised impairment in tasks sensitive to frontal lobe function including attentionalset shifting (Lange et al., 1992; Kulisevsky et al., 1998). However, early-in-the-course unmedicated PD patients show greater deficits in set shifting performance than late-in-thecourse medicated patients, strongly suggesting a positive effect of medication (Downes et al., 1989; Owen et al., 1992).

The precise relationship between cognitive impairment and catecholamine dysregulation of frontostriatal circuits is somewhat complex; there is some evidence that DA-ergic medication may have the effect of modulating the overall behavioural response by producing both deleterious as well as beneficial effects depending on several factors including drug dosage, task demands and control rates of responding (Robbins and Sahakian, 1979; Gotham et al., 1988; Arnsten et al., 1994; Swainson et al., 2000; Cools et al., 2001a; Chudasama and Robbins, 2004b). Thus, during a probabilistic reversal learning task, where reinforcement contingencies were degraded such that only $80 \%$ feedback (instead of the normal 100\%) was received on the correct stimulus, and $20 \%$ feedback being 'incorrect' (see Lawrence et al., 1999), medicated PD patients were significantly impaired because of their inability to reach a learning criterion at the reversal stage (Swainson et al., 2000). It is also possible, that learning deficits can contribute to the set shifting deficit on the ED/ID task; PD patients have difficulties in the development and maintenance of attentional sets (Flowers and Robertson, 1985; Owen et al., 1992) in addition to their deficits in shifting to an alternative set, when the demands for new rule learning are increased. As such, the ED/ ID task confounds learning and set-shifting (Swainson et al., 2000). The task-set switching paradigm (Rogers and Monsell, 1995; Cools et al., 2001a, 2001b; Mehta et al., 2004b) minimizes these effects by reducing the load on rule learning by having subjects switch between well established sets (well practiced tasks) which therefore increases the premium on set shifting. Using this task, Cools et al. (2001a) showed that LDopa withdrawal in PD patients, while having a detrimental effect on task-set switching, had a beneficial effect on probabilistic reversal learning. In addition, although the PD patients showed the classic EDS impairment, there was no difference between those patients that were 'on' or 'off' medication and thus the specific impairment on the task set switching at the 'off' stage indicates a specific deficit in reengaging a well established attentional set, a finding also observed in monkeys with 6-hydroxydopamine (6-OHDA) lesions of the caudate nucleus (Collins et al., 2000; Crofts et al., 2001). Indeed, L-Dopa is thought to work by elevating DA levels in the worst affected regions, namely the dorsal striatum (Hornykiewicz, 1974; Maruyama et al., 1996) and the effects of medication on task-set switching and reversal learning have been interpreted in terms of the 'normalization' of DA levels when potentially depleted from the fronto-dorsal striatal circuit (associated with task-set switching performance), whilst at the same time potentially 'overdosing' DA levels in a relatively intact fronto-ventral striatal circuit that is associated with reversal learning (Swainson et al., 2000). The 'DA overdosing' effect has also been observed in healthy volunteers who are impaired in probabilistic reversal learning following administration of the $\mathrm{D}_{2}$ agonist, bromocriptine while showing an improvement in spatial working memory performance (Mehta et al., 2004b). There is also evidence that DA based psychostimulant drugs may modulate set-shifting behaviour in other clinical conditions. For example, chronic amphetamine abusers are sensitive to the ED shift whereas heroin abusers are impaired in learning the ID component in the ED/ID test (Ornstein et al., 2000), and methylphenidate improves setshifting performance in ADHD patients (Mehta et al., 2004a). Together, these data argue for a specific influence of DA on the modulation of performance on tasks sensitive to frontal lobe damage and highlight the necessity to understand the state of 
patients under study in terms of clinical response as well as neurochemical pathology. Importantly, the mechanism by which DA-ergic medication in PD patients may facilitate and impede cognitive performance serves as a useful model for understanding how DA modulation may contribute to normal and abnormal cognitive states.

Nonetheless, the influence of L-Dopa medication poses difficulties of interpretation of the deficits observed in PD patients as well as other forms of neurochemical pathology seen in this condition, and there is now accumulating evidence that some of the deficits seen in PD may be related to nondopaminergic pathology, for example in the cortical differentiation of the monoaminergic and cholinergic neurotransmitter systems. Consequently, the ED/ID test suite has been employed in studies using non-human primates because of the ease with which specific neurotransmitter manipulations can be made in this species. These studies have helped elucidate the nature of the selective neurotransmitter manipulations on several aspects of cognitive performance. For example, it has been demonstrated that basal forebrain lesions that cause up to $70 \%$ cortical cholinergic depletion (Roberts et al., 1990, 1992), equivalent to that seen in non-demented cases of PD (Perry et al., 1985), selectively impaired serial reversal learning (when reversals occur consecutively within a session), implicating the relative importance of cholinergic mechanisms of the frontal cortex in the cognitive deficits associated with this disease. Thus, cortical cholinergic loss is unlikely to account for the attentional set-shifting deficit in PD patients, although it may account for other cognitive deficits including memory and learning difficulties which correlate well with cholinergic loss in patients with $\mathrm{AD}$.

Surprisingly however, the effect of frontal catecholamine depletion produced by 6-OHDA leads to enhanced set-shifting at the EDS stage, a result opposite to that of lateral PFC lesions (Roberts et al., 1994; Dias et al., 1996). Further experiments showed that monkeys with PFC DA depletion were markedly impaired in acquiring and maintaining an attentional set towards a specific perceptual dimension (Crofts et al., 2001), a finding resembling that observed in PD patients (Owen et al., 1992) and chronic schizophrenia (Pantelis et al., 1999). However, the lack of set-shifting impairment in monkeys with DA depletion from the caudate nucleus (Collins et al., 2000; Crofts et al., 2001) implicates the involvement of other neurochemical mediators other than DA that may cause a disruption to circuits outside the caudate nucleus. Recently, this hypothesis has been applied directly to monkeys with PFC 5HT (serotonin) depletion which resulted in increased perseverative responding to a previously rewarded stimulus in a visual discrimination reversal task (Clarke et al., 2004). Intriguingly, the 5-HT depletion was selective to $\mathrm{PFC}$ regions that included the OFC which is recruited during reversal learning (Dias et al., 1996). Furthermore, the analysis that PFC 5-HT depletion did not alter 5-HT or DA levels in sub-cortical structures including the dorsal and ventral striatum is consistent with the finding that striatal DA depletion does not affect the ability to reverse stimulus-reward associations (Collins et al., 2000; Crofts et al., 2001).
In humans, the effect of directly manipulating 5-HT levels has only been explored using dietary tryptophan depletion which has little effect on tasks that require the integrity of the DLPFC (Park et al., 1994) but does impair visual discrimination reversal (Park et al., 1994; Rogers et al., 1999a). These effects of neurochemical manipulations in the PFC provide some insight into the nature of the functional interactions between these neurochemical systems. It now seems likely that the central 5-HT system and its interactions with acetylcholine probably mediate reward-related information processing and this has implications for a number of neuropsychiatric disorders. For example, patients with OCD make perseverative errors (Lucey et al., 1997), they show OFC pathology (Insel and Winslow, 1992; Hermesh et al., 2003) and are often prescribed tricyclic antidepressant chlorimpramine and selective serotonin reuptake inhibitors as part of drug therapy (Zohar and Judge, 1996). Thus, the interactions between the ascending neurotransmitter systems may have to be taken into account when predicting their impact on performance.

The ED/ID test has been useful for understanding the cortical specificity and neurochemical selectivity of function in patients with frontal damage, basal ganglia disease as well as psychiatric illness. A similar discrimination and reversal paradigm has now been implemented for use with rats (Bussey et al., 1997) also using computer graphic stimuli on a touchsensitive monitor, which has made is possible to dissociate the perseverative nature of the OFC cortex (Chudasama and Robbins, 2003) from the non-perseverative new learning deficit that is sensitive to the more dorsal and lateral PFC regions in the rat (Bussey et al., 1997; Chudasama et al., 2001). Other tasks used with rats that are formally similar to the ED/ID test include a set-shifting task that uses odours and texture as the stimuli dimensions to be discriminated (Birrell and Brown, 2000) which again is highly sensitive to the OFC damage (Brown and Bowman, 2002). In addition, behavioural flexibility has also been investigated using place reversal learning tasks (e.g. Ragozzino et al., 1999) by means of laboratory mazes and are sensitive to frontal manipulations (Ragozzino et al., 1999; Delatour and Gisquet-Verrier, 2000; Dias and Aggleton, 2000).

Therefore, understanding the basic function of these different frontal sectors provides a necessary foundation on which to interpret cognitive deficits in several clinical disorders, as well as understanding the effects of selective neurotransmitter manipulations on various aspects of cognitive performance. The recent findings that modafinil, a wake-promoting agent which has psychostimulant properties, enhanced attentional set-shifting performance in adult ADHD and schizophrenia (Turner et al., 2004a, 2004b), and methylphenidate improves set-shifting in ADHD patients (Mehta et al., 2004a) indicates the psychostimulant medication may have potential as important therapy for cognitive impairment because of its beneficial effects on attentional control.

\section{Modeling spatial working memory}

Studies of localisation of function within the prefrontal cortex have been more feasible in monkeys and rats, than in 
humans, because of the advantage of being able to produce selective neuroanatomical and neurochemical manipulations. It is now accepted that deficits shown by animals on the delayed response procedure, formally a test of spatial short-term memory, is associated with damage to the DLPFC. The deficit is thought to relate to the way in which the PFC controls how internal representations come to affect action (Goldman-Rakic, 1987) specifically by holding information 'on-line.' Animals with frontal ablations are consistently impaired on this task which made it well suited for comparing the effects of frontal lesions in experimental animals with clinical conditions such as PD although it is difficult to decompose executive functions of response selection, strategy and organisation that may well contaminate the overall working memory deficit.

Nevertheless, the motivating factor in designing the selfordered working memory task for CANTAB was the simple reason that a major aspect of executive function is attention to action, especially in behavioural circumstances that require planning and organisation. Its basic design, which is a modification of the original subject-ordered pointing task (Petrides and Milner, 1982), is derived from the spatial search task used with monkeys (Passingham, 1985) and is related to the radial maze working memory task for rats (Olton, 1982). In brief, the patient must search through a number of boxes on a screen to collect tokens and produce their own 'self-ordered' sequence of responses. Patients with frontal lobe damage continued to return to boxes in which a token had already been found making 'between search errors' (Owen et al., 1990). These patients were also less proficient at using a strategy to facilitate their performance, suggesting that their overall deficit in working memory may be confounded by a deficit in planning and organisational skills. Several other groups of patients such as $\mathrm{AD}$ and $\mathrm{PD}$ patients and temporal lobe patients also show between search errors indicating some level of frontal pathology, but they do not show the significant deficit in strategy (Sahgal et al., 1992; Owen et al., 1995, 1996) whereas Huntington's and Korsakoff's patients exhibit deficits in both strategy and memory performance (Joyce and Robbins, 1991; Lawrence et al., 1996); these deficits may arise due to a neural circuitry that associates the frontal cortex with diencephalic structures, rather than medial temporal lobe and basal ganglia.

The self-ordered test clearly requires the integrity of the frontal cortex and has been directly examined in monkeys with frontal lesions that have been shown to be profoundly impaired on this task, and are highly perseverative due to the disruption of inhibitory control mechanisms necessary to avoid reselecting the previously chosen stimulus (Roberts et al., 1994). That PFC DA depletion in monkeys had no effect on any aspect of performance on the self-ordered task (Collins et al., 1998) clearly dissociates its rather specific influence in facilitating shifting between attentional dimensions. Surprisingly, the only task in which DA depletion mimicked the effect of PFC lesions was in spatial delayed response, a classic working memory task. The specificity of this deficit in monkeys is relevant to children with the genetic developmental disorder of phenylketonuria or PKU, who are thought to show reduced levels of DA in the frontal cortex because of their inability to convert phenylala- nine into the DA precursor, tyrosine (Diamond et al., 1997, 2004). In addition to showing widespread brain damage and severe mental retardation (e.g. Cowie, 1971), children with PKU show poor spatial working memory performance and setshifting abilities (Luciana et al., 2001), but do not show impaired performance on the self-ordered pointing task (Diamond et al., 1997). However, a different pattern of behaviour is evidenced in normal developing children with homozygous Methionine (Met) polymorphism of the catechol$O$-methyltransferase (COMT) gene, which results in slower prefrontal DA catabolism, thus allowing DA to remain active in extracellular space longer (Lotta et al., 1995; Diamond et al., 2004). Opposite to the effects of reduced DA in PKU, the Met polymorphism genotype resulted in children showing better performance on a task requiring working memory, but again not on self-ordered pointing (Diamond et al., 2004). These data clearly confirm that performance on the self-ordered pointing task is insensitive to levels of PFC DA and the differential sensitivity of PFC DA on distinct cognitive processes.

The above findings also support the accumulating evidence that DA in the frontal cortex has an important modulatory effect on working memory performance. In monkeys this is assessed using the delayed response tasks; DA receptor antagonists produce an impairment (Sawaguchi and Goldman-Rakic, 1991), low dose DA receptor agonists enhance performance (Arnsten et al., 1994; Cai and Arnsten, 1997) and increased DA turnover disrupts performance (Murphy et al., 1996) according to an inverted ' $U$ ' shaped function. Recently, these findings have been mimicked in rats using maze paradigms (Zahrt et al., 1997; Floresco and Phillips, 2001) and automated operant tasks that have highlighted an interesting attention-working memory interaction via PFC DA modulation (Granon et al., 2000; Chudasama and Robbins, 2004b). Evidently, although PFC DA depletion failed to show a direct role in various performance measures of the self-ordered task, it is possible that different cognitive processes may be differentially affected by fluctuations in prefrontal DA that may ultimately modulate behaviour. There is evidence in humans that DA manipulations influence certain cognitive processes in normal volunteers. Spatial shortterm working memory tasks that require information to be held in memory and sequentially manipulated can be enhanced by low doses of $\mathrm{DA}_{2}$ receptor agonists such as bromocriptine, whilst impairing the ability to reverse a learned probabilistic reversal task (Mehta et al., 2001) both processes known to depend on the frontal lobes (Owen et al., 1995). In contrast, the $\mathrm{DA} \mathrm{D}_{2}$ receptor antagonist, sulpiride, impairs several spatial tasks of working memory as well as attentional set-shifting and the more robust task set-switching paradigm (Mehta et al., 1999, 2004b) and yet improves attentional selection in rats with PFC lesions (Passetti et al., 2003). These effects were in the absence of any sedative or motoric effects of the drug. The anatomical distribution of $\mathrm{DA} \mathrm{D}_{2}$ receptors in the brain suggests that the major site of action for sulpiride is in the striatum (Camps et al., 1989), coupled with the finding that preclinical HD patients show correlations between accurate performance on working memory tasks with $\mathrm{D}_{2}$ receptor ligand binding potentials in the caudate and putamen (Lawrence et al., 1998b). 
It is also relevant that monkeys with striatal DA depletion are impaired on spatial working memory (Collins et al., 2000). Clearly, although the precise mechanisms by which DA modulates cognitive performance are still unknown, experimental studies in both humans and animals add to the growing body of evidence implicating central DA systems in cognitive processes dependent on intact frontostriatal connections.

Therefore, it appears that the executive deficit in spatial working memory observed in frontal patients has a considerable degree of selectivity but it is not simply produced by damage to the PFC. It seems likely that performance on this task is a product of interactions between cortical and subcortical structures, and their neurochemical innervations, especially DA which serves to regulate performance depending on the precise task requirement and baseline levels of DA. Much of this work has emerged from studies using experimental animals because of the availability of specific receptor agents that are not always available for use in humans. Importantly, the results of Collins et al. (1998) demonstrate that the effects of lesioning ascending DA projections in monkeys are not always equivalent to lesions of the prefrontal cortex itself.

\section{Modeling decision-making and impulsivity}

Converging neuropsychological and neuroimaging evidence suggests that abnormalities in practical real-life decisionmaking form a prominent part of the profile of the cognitive deficit associated with patients that have frontal damage restricted to the ventromedial PFC (VMPFC) that includes the orbitofrontal region (Damasio, 1994; Bechara et al., 1998, 1999; Rogers et al., 1999b; Rahman et al., 1999; Manes et al., 2002). Such cognitive deficits are considered in the context of risk-taking or impulsivity because patients tend to pursue inappropriate actions, often without foresight, that are immediately rewarding, but are likely to have undesirable consequences for the patient's well being in the long-term. In humans, abnormalities in decision-making have been quantified successfully using the Iowa gambling task (e.g. Bechara et al., 1994) which emphasizes the learning of reward and punishment associations by making a series of card selections that result in either a net gain or net loss. Patients with VMPFC damage are consistently impaired in this task because they persist in drawing cards from the high risk/high penalty decks leading to an overall reward loss (Damasio, 1994; Bechara et al., 1994, 2000). Patients with damage to the DLPFC perform within the normal range but are sensitive to tests of working memory showing a double dissociation of impairment in decision-making and working memory (Bechara et al., 1998). As such, measures of decision-making and impulsivity may be useful as functional markers of ventral prefrontal cortex damage in several patient groups that show sociopathological tendencies (Damasio et al., 1990; Lapierre et al., 1995; Blair et al., 2001) or substance abuse (Volkow and Fowler, 2000; Bechara et al., 2001; Bolla et al., 2003).

Some of the principles of the Iowa gambling task have been incorporated into the Cambridge Gamble Task and as part of CANTAB, has been decomposed to assess decision-making abilities uncontaminated by learning and working memory confounds, simply by presenting all the information needed to make a decision on the computer screen. In brief, the subject is required to make a probability judgment of whether a token is hidden beneath a red or blue box presented on a screen and bet a proportion of their total points, reflecting confidence in their decision (for details, see Clark et al., 2004). The task also aims to dissociate motor impulsivity from risk-taking behaviour: fixed bets are displayed on the screen in either ascending or descending order, and the subject must make a response only when the amount displayed is the amount they would like to bet. A truly impulsive subject is less able to 'wait' and tends to respond too early thus placing high bets when they are descending, and place low bets when they are ascending resulting in overall loss in reward.

The Cambridge Gamble Task is sensitive to several patient groups with implicated VMPFC pathology; FTD patients (Rahman et al., 1999), those with aneurysms of the anterior communicating artery which supplies blood to the medial and ventral PFC (Mavaddat et al., 2000), and those with large frontal lesions (Manes et al., 2002) make accurate probability judgements and have slow deliberation times, but demonstrate high risk behaviour as evidenced by their need to place high bets in both ascending and descending conditions. By way of comparison, patients with borderline personality disorder who show fronto-executive deficits (O'Leary et al., 1991; Bazanis et al., 2002) also show slow deliberation times but were unable to suppress their responses thus placing bets too early in both ascending and descending conditions indicating maladaptive impulsive tendencies. Indeed, decision-making may recruit neural activity from multiple ventromedial frontal regions specifically within the inferior and orbital PFC (Rogers et al., 1999b) which may explain the apparently greater incidence of decision-making deficit in patients with OFC damage compared with those sustaining damage to dorsolateral or dorsomedial areas (Bechara et al., 1998; Rogers et al., 1999a). However, patients with early HD, who often have 'frontoexecutive' cognitive deficits, show intact decision-making ability on the Cambridge Gamble Task (Watkins et al., 2000) although they may be impaired on the more complex Iowa gambling task (see Stout et al., 2001). They also show deficits during reversal learning (Lange et al., 1995) that is normally sensitive to OFC lesions (Dias et al., 1996). Decision-making requires the ability to select appropriate responses which require flexibility in adaptation to changing reward contingencies and thus, deficits in reversal learning may relate to high risk-taking or impulsive behaviours that lead to abnormal decision making abilities. The parallels between decisionmaking and reversal learning impairments have been provided in detail elsewhere (see Clark et al., 2004). Suffice to say, however, that PD patients, similar to HD patients, perform the Iowa gambling task within the normal range (Czernecki et al., 2002; Stout et al., 2001) suggesting that the reversal learning deficits may reflect the progression of the disease that has been observed in basal ganglia disorders through the striatum, and indicate a considerable degree of specificity of decision-making effects to ventral regions of the prefrontal cortex. 


\subsection{Studies with non-human primates}

There is a paucity of lesion and pharmacological literature on primates and risk taking behaviour, but performance of monkeys on Go/No-go tasks is relevant not only because it is a task that assesses the ability to actively inhibit inappropriate impulses, but also because the same paradigm has been used extensively in clinical settings (e.g. Drewe, 1975) including patients with orbitofrontal damage (Leimkuhler and Mesulam, 1985; Malloy et al., 1993). In the Go/No-go procedure (e.g. McEnaney and Butter, 1969; Iversen and Mishkin, 1970), the monkey learns to make a response in the presence of a positive stimulus (a ' $\mathrm{go}$ ' trial), and inhibit a response in the presence of a negative stimulus (a 'no-go' trial) for a fixed duration. No-go errors (responses that are made during the No-go trial) are committed because of the failure to inhibit or delay the pre-potent tendency to respond. In monkeys, this inhibitory deficit of impulse control is sensitive to damage to the inferior prefrontal convexity (Iversen and Mishkin, 1970) which is the critical tissue that was often included in lesions of the dorsolateral, as well as the ventral orbital surface of the prefrontal cortex. Dorsolateral lesions that spare the lateral portion of the inferior convexity, do not impair Go/No-go performance (Lawicka et al., 1975) but consistent with its role in spatial and mnemonic functions, produce severe deficits in delayed response tasks (Pribram, 1961; Goldman and Rosvold, 1970; Goldman-Rakic, 1987). By comparison, orbital lesions that are extended to include the inferior prefrontal convexity produce a marked difficulty in suppressing the No-go response (Lawicka et al., 1975; Iversen and Mishkin, 1970; Butters et al., 1973) similar to that observed in patients with OFC damage (Leimkuhler and Mesulam, 1985; Malloy et al., 1993; see also Casey et al., 1997a). That patient's with DLPFC damage do not impair Go/No-go performance (Drewe, 1975; Décary and Richer, 1995) further demonstrates the selectivity of the ventral orbitofrontal region in the inhibitory control of impulsive behaviour.

Hence, the Go/No-go task has useful translational properties; it is a laboratory test that can be used with humans and monkeys, and rats (e.g. Setlow et al., 2003), and is a test of inhibitory-impulsive control capable of distinguishing orbitofrontal from dorsolateral pathology. However, in addition to with-holding a pre-potent response, a critical aspect of Go/Nogo performance is the ability to select the appropriate action based on anticipated reward (Petrides, 1982, 1986; Balleine and Dickinson, 1998). Such stimulus-response associations are thought to rely, in part, on the integrity of the basal ganglia (Mishkin et al., 1984; Reading et al., 1991; Knowlton et al., 1996) and their projections to selective regions of the frontal cortex (Johnson et al., 1968; Killcross and Coutureau, 2003). Thus, rhesus monkeys with lesions to the periarcuate region of the DLPFC only exhibit deficits in tasks where they are required to select between alternative responses as in a conditional motor task (for review, see Petrides, 1987) or indeed, delayed alternation (see Fuster, 1980), a finding mimicked by lesions made to the dorsal part of the head of the caudate nucleus (Battig et al., 1960). Likewise, similar to the performance deficit in Go/No-go tasks, monkeys with lesions to the ventral sector of the caudate nucleus, retard operant extinction such that these monkeys continue to emit a bar response even though they are not rewarded for doing so (Butter et al., 1963; Divac et al., 1967); another task that is sensitive to ventral orbital damage, and is not affected by DLPFC ablations (Divac et al., 1967). Together, these observations suggest that the frontostriatal system of projections may ultimately provide two independent mechanisms; a dorsal mechanism for the coordination of motor actions and 'habits' (Mishkin et al., 1984; Killcross and Coutureau, 2003) that is known to deteriorate in patients with striatal pathology (e.g. Saint-Cyr et al., 1988), and a ventral mechanism for the inhibition of stimulus-response-reward associations that is associated with pathological conditions such as OCD (Baxter et al., 1988; Swedo et al., 1989) and ADHD (Trommer et al., 1991; Casey et al., 1997b).

\subsection{Studies in rats}

There is increasing evidence suggesting that abnormalities in serotonergic innervation of the frontal cortex may contribute to the decision-making deficit (Park et al., 1994; Rogers et al., 1999c). In rodents, it has been possible to examine with specificity, the direct effects of manipulating the serotoninergic system. In support of the general hypothesis that decreased 5-HT function increases impulsivity (e.g. Soubrié, 1986), global 5-HT lesions in rats using 5-7 dihydroxytryptamine (5,7-DHT) reliably increases impulsive responding in several tasks including Go/No-go tasks and the 5CSRTT, which incorporate a 'waiting' component during which the animal must resist the immediate impulse to respond (e.g. Wogar et al., 1993; Fletcher, 1995; Harrison et al., 1997, 1999; Winstanley et al., 2004a), and is similar to the effects of lesioning the ventromedial prefrontal cortex (Chudasama et al., 2003a). Unlike the requirement to withhold or inhibit an impulsive response, the responding parameters are different in the delay discounting procedure in which the animal is presented with a choice of selecting a response that results in a small but immediate reward, or a response that leads to a larger delayed one (Mazur, 1987; Evenden and Ryan, 1996) and therefore, similar to human decision-making, the delay discounting task requires the animal to use experience of reward to guide future selection of responses. Consistent with the human literature, rats with OFC lesions increase their preference for smaller, immediate rewards (Mobini et al., 2002) whereas lesions made to dorsomedial regions remain unimpaired on this task (Cardinal et al., 2001). However, consistent impairments in impulsive choice following 5-HT depletion in rats have not been observed (e.g. Bizot et al., 1999; Mobini et al., 2000; Winstanley et al., 2004b). Evidently, not all measures of impulsivity are uniformly affected by 5-HT depletion, supporting the view that impulsivity is a non-unitary construct which can be fractionated into several varieties (Evenden, 1999; Winstanley et al., 2004a). For example, another aspect of impulsivity is the ability to stop a response that has already been initiated (Logan, 1994; Logan et al., 1997) and can be assessed using the stop-signal reaction time (SSRT) task in rats (Eagle and Robbins, 2003a, 2003b), and in humans (e.g. de Wit et al., 2000). Patients with impulsive disorders, such as 
ADHD (Oosterlaan et al., 1998; Rubia et al., 1998; Aron et al., 2003a), or frontal and striatal pathology (Aron et al., 2003b; Rieger et al., 2003), produce significant impairments in their ability to stop in the SSRT. However, although rats with dorsomedial striatal lesions are also slow to stop, lesions of the dorsomedial PFC are without effect in the SSRT task (Eagle and Robbins, 2003a, 2003b). Furthermore, unlike the behavioural effects on impulsive choice, rats with lesions of the ventral striatum (Nac) do not affect any aspect of SSRT performance. Clearly, different striatal regions mediate different forms of impulsivity that can be measured by different inhibitoryimpulsive tasks.

In rats, 5-HT depletions have also shown to increase speed and number of responses in a pavlovian autoshaping task in which animals learn to approach reward predictive of reward (Winstanley et al., 2004a) and selective lesions of the OFC impair pavlovian autoshaping task (Chudasama and Robbins, 2003) suggesting that the pathology of the OFC and its serotonergic innervation may contribute to a dysfunctional reward system. It follows therefore, that aspects of impulsivity may be present in behaviours that are elicited through stimulusreward associations and it has been suggested that such associations may play an important role in the maintenance and relapse of drug seeking behaviour (Childress et al., 1992; Jentsch and Taylor, 1999; Everitt and Robbins, 2000; Volkow and Fowler, 2000). However, unlike the impulsive tendency to seek reward in drug abusers, children with ADHD show an impulsive tendency specific to seeking stimulation by needing immediate, frequent and intense reinforcers to maintain appropriate behaviour (Haenlein and Caul, 1987; Barkley, 1989).

The effects of DA drugs on reward-related behaviour as a measure of impulsivity has been addressed in rats; amphetamine administration (a non selective DA releaser) increases the value of delayed rewards (i.e. decreased impulsivity), whereas DA $D_{2}$ but not $D_{1}$ receptor antagonists decreased the value of delayed rewards and thus increased impulsivity (Wade et al., 2000; de Wit et al., 2002). Although it is clear that DA modulates choice between rewards, the effects of DA manipulations are quite complex, particularly with respect to drug dosage, rate dependency and neuroanatomical locus of action. For example, the Nac has also been implicated in regulating choice between reinforcers that may be under the control of dopaminergic mechanisms (Cardinal et al., 2001). That drug abusers show deficits in decision-making tasks (Bechara et al., 2001; Rogers and Robbins, 2001; Clark and Robbins, 2002) and children with ADHD are often insensitive to promise of reward and threat of punishment (Pelham and Murphy, 1986; Solanto, 2001), suggest that frontal pathology may be a core problem in disorders of addiction and ADHD (Bechara et al., 2001; Rogers and Robbins, 2001; Clark and Robbins, 2002; Solanto, 2001).

\section{Concluding comments}

In this survey, we have provided an integrative cognitive and comparative account of the evidence that implicates frontostriatal modulation in neurodegenerative and psychiatric disorders. Specifically, we have illustrated the view that there are certain cognitive functions where extrapolation from animal behaviour has positively informed our investigation of cognitive functions in humans (see Table 1). We have discussed specific examples of 'animal to human approaches' where paradigms originally established for use in animals (e.g. delayed response), have directed the design and development of analogous tests for use in humans (e.g. self-ordered working memory). In addition, although human experimental psychology has provided several ways of operationalizing perhaps conceptual and abstract cognitive constructs, it has now become apparent that many of these constructs can be adapted quite easily for use in experimental animals, the obvious example being the animal ED/ID test based upon the principles of the human WCST. Thus, animal experimental psychology has benefited in the opposite direction by means of 'human to animal' approaches. Together, these advances have been particularly useful in terms of establishing the necessary and sufficient form of neuroanatomical and neurochemical pathology for specific cognitive deficits in a range of brain and behaviour disorders. For the purpose of this paper, however, we have focused on behavioural tasks sensitive to frontal lobe function and as such appear to be useful markers for characterising frontal lobe pathology in several clinical groups. The observation of common cognitive deficits in patient groups with different diagnoses, such as schizophrenia, ADHD and dementia, reinforces the possibility that the same neural substrates are being compromised in these different disorders, at least at some level, for example, either early or late in the course of the disease.

\section{Acknowledgments}

This work was supported by a Programme Grant from the Wellcome Trust (TWR) and completed within the University of Cambridge Behavioural and Clinical Neuroscience Institute funded by a joint award from the Medical Research Council and the Wellcome Trust. TWR consults for Cambridge Cognition. YC was supported by Cambridge Cognition.

\section{References}

Abas, M.A., Sahakian, B.J., Levy, R., 1990. Neuropsychological deficits and CT scan changes in elderly depressives. Psychological Medicine 20, 507520 .

Alexander, G.E., DeLong, M.R., Strick, P.L., 1986. Parallel organization of functionally segregated circuits linking basal ganglia and cortex. Annual Review of Neuroscience 9, 357-381.

Annett, L.E., Rogers, D.C., Hernandez, T.D., Dunnett, S.B., 1992. Behavioural analysis of unilateral monoamine depletion in the marmoset. Brain 115, 825-856.

Arnsten, A.F., Cai, J.X., Murphy, B.L., Goldman-Rakic, P.S., 1994. Dopamine D1 receptor mechanisms in the cognitive performance of young adult and aged monkeys. Psychopharmacology 116, 143-151.

Aron, A.R., Dowson, J.H., Sahakian, B.J., Robbins, T.W., 2003a. Methylphenidate improves response inhibition in adults with attention-deficit/hyperactivity disorder. Biological Psychiatry 54, 1465-1468.

Aron, A.R., Fletcher, P.C., Bullmore, E.T., Sahakian, B.J., Robbins, T.W., 2003b. Stop-signal inhibition disrupted by damage to right inferior frontal gyrus in humans. Nature Neuroscience 6, 115-116. 
Balleine, B.W., Dickinson, A., 1998. Goal-directed instrumental action: contingency and incentive learning and their cortical substrates. Neuropharmacology 37, 407-419.

Barense, M.D., Fox, M.T., Baxter, M.G., 2002. Aged rats are impaired on an attentional set-shifting task sensitive to medial frontal cortex damage in young rats. Learning and Memory 9, 191-201.

Barkley, R.A., 1989. The problem of stimulus control and rule-governed behavior in attention deficit disorder with hyperactivity. In: Bloomingdale, L.M., Swanson, J. (Eds.), Attention Deficit Disorder: Current Concepts and Emerging Trends in Attentional and Behavioral Disorders of Childhood. Pergamon Press, Elmsford, NY, pp. 203-232.

Battig, K., Rosvold, H.E., Mishkin, M., 1960. Comparison of the effects of frontal and caudate lesions on delayed response and alternation in monkeys. Journal of Comparative and Physiological Psychology 53, 400-404.

Baunez, C., Robbins, T.W., 1997. Bilateral lesions of the subthalamic nucleus induce multiple deficits in an attentional task in rats. European Journal of Neuroscience 9, 2086-2099.

Baunez, C., Robbins, T.W., 1999. Effects of dopamine depletion of the dorsal striatum and further interaction with subthalamic nucleus lesions in an attentional task in the rat. Neuroscience 92, 1343-1356.

Baxter Jr., L.R., Schwartz, J.M., Mazziotta, J.C., Phelps, M.E., Pahl, J.J., Guze, B.H., Fairbanks, L., 1988. Cerebral glucose metabolic rates in nondepressed patients with obsessive-compulsive disorder. The American Journal of Psychiatry 145, 1560-1563.

Bazanis, E., Rogers, R.D., Dowson, J.H., Taylor, P., Meux, C., Staley, C., Nevinson-Andrews, D., Taylor, C., Robbins, T.W., Sahakian, B.J., 2002. Neurocognitive deficits in decision-making and planning of patients with DSM-III-R borderline personality disorder. Psychological Medicine 32, 1395-1405.

Bechara, A., Damasio, A.R., Damasio, H., Anderson, S.W., 1994. Insensitivity to future consequences following damage to human prefrontal cortex. Cognition 50, 7-15.

Bechara, A., Damasio, H., Damasio, A.R., Lee, G.P., 1999. Different contributions of the human amygdala and ventromedial prefrontal cortex to decision-making. The Journal of Neuroscience 19, 5473-5481.

Bechara, A., Damasio, H., Tranel, D., Anderson, S.W., 1998. Dissociation of working memory from decision making within the human prefrontal cortex. The Journal of Neuroscience 18, 428-437.

Bechara, A., Dolan, S., Denburg, N., Hindes, A., Anderson, S.W., Nathan, P.E., 2001. Decision-making deficits, linked to a dysfunctional ventromedial prefrontal cortex, revealed in alcohol and stimulant abusers. Neuropsychologia 39, 376-389.

Bechara, A., Tranel, D., Damasio, H., 2000. Characterization of the decisionmaking deficit of patients with ventromedial prefrontal cortex lesions. Brain 123, 2189-2202.

Berman, K.F., Weinberger, D.R., 1990. Lateralisation of cortical function during cognitive tasks: regional cerebral blood flow studies of normal individuals and patients with schizophrenia. Journal of Neurology, Neurosurgery, and Psychiatry 53, 150-160.

Birrell, J.M., Brown, V.J., 2000. Medial frontal cortex mediates perceptual attentional set shifting in the rat. The Journal of Neuroscience 20, 43204324.

Bizot, J.C., Bihan, C., Puech, A.J., Hamon, M., Thiébot, M.H., 1999. Serotonin and tolerance to delay of reward in rats. Psychopharmacology 146, 400412.

Blair, R.J., Colledge, E., Mitchell, D.G., 2001. Somatic markers and response reversal: is there orbitofrontal cortex dysfunction in boys with psychopathic tendencies? Journal of Abnormal Child Psychology 29, 499-511.

Bolla, K.I., Eldreth, D.A., London, E.D., Kiehl, K.A., Mouratidis, M., Contoreggi, C., Matochik, J.A., Kurian, V., Cadet, J.L., Kimes, A.S., Funderburk, F.R., Ernst, M., 2003. Orbitofrontal cortex dysfunction in abstinent cocaine abusers performing a decision-making task. Neuroimage 19, 1085-1094.

Bowman, E.M., Brown, V.J., Kertzman, C., Schwarz, U., Robinson, D.L., 1993. Covert orienting of attention in macaques. I. Effects of behavioral context. Journal of Neurophysiology 70, 431-443.

Brasted, P.J., Robbins, T.W., Dunnett, S.B., 1999. Distinct roles for striatal subregions in mediating response processing revealed by focal excitotoxic lesions. Behavioral Neuroscience 113, 253-264.
Brown, V.J., Bowman, E.M., 2002. Rodent models of prefrontal function. Trends in Neuroscience 25, 340-343.

Brown, V.J., Robbins, T.W., 1989. Deficits in response space following unilateral striatal dopamine depletion in the rat. The Journal of Neuroscience 9 , 983-989.

Brozoski, T.J., Brown, R.M., Rosvold, H.E., Goldman, P.S., 1979. Cognitive deficit caused by regional depletion of dopamine in prefrontal cortex of rhesus monkey. Science 205, 929-932.

Bussey, T.J., Muir, J.L., Robbins, T.W., 1994. A novel automated touchscreen procedure for assessing learning in the rat using computer graphic stimuli. Neuroscience Research Communication 15, 103-109.

Bussey, T.J., Everitt, B.J., Robbins, T.W., 1997. Dissociable effects of cingulate and medial frontal cortex lesions on stimulus-reward learning using a novel pavlovian autoshaping procedure for the rat: implications for the neurobiology of emotion. Behavioral Neuroscience 111, 1-12.

Butter, C.M., Mishkin, M., Rosvold, H.E., 1963. Conditioning and extinction of a food-rewarded response after selective ablations of frontal cortex in rhesus monkeys. Experimental Neurology 7, 65-75.

Butters, N., Butter, C., Rosen, J., Stein, D., 1973. Behavioral effects of sequential and one-stage ablations of orbital prefrontal cortex in the monkey. Experimental Neurology 39, 204-214.

Cai, J.X., Arnsten, A.F., 1997. Dose-dependent effects of the dopamine D1 receptor agonists A77636 or SKF81297 on spatial working memory in aged monkeys. The Journal of Pharmacology and Experimental Therapeutics 283, 183-189.

Camps, M., Cortes, R., Gueye, B., Probst, A., Palacios, J.M., 1989. Dopamine receptors in human brain: autoradiographic distribution of D2 sites. Neuroscience 28, 275-290.

Cardinal, R.N., Pennicott, D.R., Sugathapala, C.L., Robbins, T.W., Everitt, B.J., 2001. Impulsive choice induced in rats by lesions of the nucleus accumbens core. Science 292, 2499-2501.

Carli, M., Evenden, J.L., Robbins, T.W., 1985. Depletion of unilateral striatal dopamine impairs initiation of contralateral actions and not sensory attention. Nature 313, 679-682.

Carli, M., Jones, G.H., Robbins, T.W., 1989. Effects of unilateral dorsal and ventral striatal dopamine depletion on visual neglect in the rat: a neural and behavioural analysis. Neuroscience 29, 309-327.

Carli, M., Robbins, T.W., Evenden, J.L., Everitt, B.J., 1983. Effects of lesions to ascending noradrenergic neurons on performance on a 5-choice serial reaction time task in rats: implications for theories of dorsal noradrenergic bundle function based on selective attention and arousal. Behavioural Brain Research 9, 361-380.

Castellanos, F.X., 1996. Neuroimaging studies of ADHD. In: Solanto, M.V., Arnsten, A.F.T., Castellanos, F.X. (Eds.), Stimulant Drugs and ADHD: Basic and Clinical Neuroscience. Oxford UP, New York, pp. 243257.

Castellanos, F.X., Giedd, J.N., Eckburg, P., Marsh, W.L., Vaituzis, A.C., Kaysen, D., Hamburger, S.D., Rapoport, J.L., 1994. Quantitative morphology of the caudate nucleus in attention deficit hyperactivity disorder. The American Journal of Psychiatry 151, 1791-1796.

Casey, B.J., Trainor, R., Orendi, J.L., Schubert, A.B., Nystrom, L.E., Geidd, J.N., Castellanos, F.X., Haxby, J.V., Noll, D.C., Cohen, J.D., Forman, S.D., Dahl, R.E., Rapoport, J.L., 1997a. A developmental functional MRI study of prefrontal activation during performance of a Go-No-Go task. Journal of Cognitive Neuroscience 9, 835-847.

Casey, B.J., Castellanos, F.X., Giedd, J.N., Marsh, W.L., Hamburger, S.D., Schubert, A.B., Vauss, Y.C., Vaituzis, A.C., Dickstein, D.P., Sarfatti, S.E., Rapoport, J.L., 1997b. Implication of right frontostriatal circuitry in response inhibition and attention-deficit/hyperactivity disorder. Journal of the American Academy of Child and Adolescent Psychiatry 36, 374383.

Childress, A.R., Ehrman, R., Roohsenow, D.J., Robbins, S.J., O’Brien, C.P., 1992. Classically conditioned factors in drug dependence. In: Lowinson, W., Luiz, P., Millman, R.B., Langard, J.G. (Eds.), Substance Abuse: A Comprehensive Textbook. Williams \& Watkins, Baltimore, USA.

Chudasama, Y., Bussey, T.J., Muir, J.L., 2001. Effects of selective thalamic and prelimbic cortex lesions on two types of visual discrimination and reversal learning. European Journal of Neuroscience 14, 1009-1020. 
Chudasama, Y., Muir, J.L., 2001. Visual attention in the rat: a role for the prelimbic cortex and thalamic nuclei? Behavioral Neuroscience 115, 417428.

Chudasama, Y., Passetti, F., Rhodes, S.E.V., Lopian, D., Desai, A., Robbins, T.W., 2003a. Dissociable aspects of performance on the 5 choice serial reaction time task following lesions of the dorsal anterior cingulate, infralimbic and orbitofrontal cortex in the rat: differential effects on selectivity, impulsivity and compulsivity. Behavioural Brain Research 146, 105-119.

Chudasama, Y., Baunez, C., Robbins, T.W., 2003b. Functional disconnection of the medial prefrontal cortex and subthalamic nucleus in attentional performance: evidence for corticosubthalamic interaction. The Journal of Neuroscience 23, 5477-5485.

Chudasama, Y., Robbins, T.W., 2003. Dissociable contributions of the orbitofrontal and infralimbic cortex to pavlovian autoshaping and discrimination reversal learning: further evidence for the functional heterogeneity of the rodent frontal cortex. The Journal of Neuroscience 23, 8771-8780.

Chudasama, Y., Robbins, T.W., 2004a. Psychopharmacological approaches to modulating attention in the five-choice serial reaction time task: implications for schizophrenia. Psychopharmacology 174, 86-98.

Chudasama, Y., Robbins, T.W., 2004b. Dopaminergic modulation of visual attention and working memory in the rodent prefrontal cortex. Neuropsychopharmacology 29, 1628-1636.

Chudasama, Y., Dalley, J.W., Nathwani, F., Bouger, P., Robbins, T.W., 2004c. Cholinergic modulation of visual attention and working memory: dissociable effects of basal forebrain 192-IgG-saporin lesions and intraprefrontal infusions of scopolamine. Learning and Memory 11, 78-86.

Christakou, A., Robbins, T.W., Everitt, B.J., 2001. Functional disconnection of a prefrontal cortical-dorsal striatal system disrupts choice reaction time performance: implications for attentional function. Behavioral Neuroscience $115,812-825$.

Christakou, A., Robbins, T.W., Everitt, B.J., 2004. Prefrontal cortical-ventral striatal interactions involved in affective modulation of attentional performance: implications for corticostriatal circuit function. The Journal of Neuroscience 24, 773-780.

Clark, L., Cools, R., Robbins, T.W., 2004. The neuropsychology of ventral prefrontal cortex: decision-making and reversal learning. Brain and Cognition 55, 41-53.

Clark, L., Manes, F., Antoun, N., Sahakian, B.J., Robbins, T.W., 2003. The contributions of lesion laterality and lesion volume to decision-making impairment following frontal lobe damage. Neuropsychologia 41, 14741483.

Clark, L., Robbins, T.W., 2002. Decision-making deficits in drug addiction. Trends in Cognitive Science 6, 361-363.

Clarke, H.F., Dalley, J.W., Crofts, H.S., Robbins, T.W., Roberts, A.C., 2004. Cognitive inflexibility after prefrontal serotonin depletion. Science 304, $878-880$.

Cole, B.J., Robbins, T.W., 1989. Effects of 6-hydroxydopamine lesions of the nucleus accumbens septi on performance of a 5-choice serial reaction time task in rats: implications for theories of selective attention and arousal. Behavioural Brain Research 33, 165-179.

Collins, P., Roberts, A.C., Dias, R., Everitt, B.J., Robbins, T.W., 1998. Perseveration and strategy in a novel spatial self-ordered sequencing task for nonhuman primates: effects of excitotoxic lesions and dopamine depletions of the prefrontal cortex. Journal of Cognitive Neuroscience 10, 332 354.

Collins, P., Wilkinson, L.S., Everitt, B.J., Robbins, T.W., Roberts, A.C., 2000. The effect of dopamine depletion from the caudate nucleus of the common marmoset (Callithrix jacchus) on tests of prefrontal cognitive function. Behavioral Neuroscience 114, 3-17.

Cools, R., Barker, R.A., Sahakian, B.J., Robbins, T.W., 2001a. Enhanced or impaired cognitive function in Parkinson's disease as a function of dopaminergic medication and task demands. Cerebral Cortex 11, 11361143.

Cools, R., Barker, R.A., Sahakian, B.J., Robbins, T.W., 2001b. Mechanisms of cognitive set flexibility in Parkinson's disease. Brain 124, 2503-2512.

Connell, P.H., 1958. Amphetamine Psychosis. Maudsley Monograph No. 5. Oxford University Press, London.
Cowie, V.A., 1971. Neurological and psychiatric aspects of phenylketonuria. In: Bickel, H., Hudson, F., Woolf, L. (Eds.), Phenylketonuria and Some Other Inborn Errors or Amino Acid Metabolism. Theime, Stuttgart, pp. 29-39.

Creese, I., Iversen, S.D., 1975. The pharmacological and anatomical substrates of the amphetamine response in the rat. Brain Research 83, 419-436.

Crofts, H.S., Dalley, J.W., Collins, P., Van Denderen, J.C., Everitt, B.J., Robbins, T.W., Roberts, A.C., 2001. Differential effects of 6-OHDA lesions of the frontal cortex and caudate nucleus on the ability to acquire an attentional set. Cerebral Cortex 11, 1015-1026.

Czernecki, V., Pillon, B., Houeto, J.L., Pochon, J.B., Levy, R., Dubois, B., 2002. Motivation, reward, and Parkinson's disease: influence of dopatherapy. Neuropsychologia 40, 2257-2267.

Dalley, J.W., Theobald, D.E., Pereira, E.A.C., Li, P.M.M.C., Robbins, T.W., 2002. Specific abnormalities in serotonin release in the prefrontal cortex of isolation reared rats measured during behavioural performance of a task assessing visuospatial attention and impulsivity. Psychopharmacology 164, 329-340.

Dalley, J.W., Thomas, K.L., Howes, S.R., Tsai, T.H., Aparicio-Legarza, M.I., Reynolds, G.P., Everitt, B.J., Robbins, T.W., 1999. Effects of excitotoxic lesions of the rat prefrontal cortex on CREB regulation and presynaptic markers of dopamine and amino acid function in the nucleus accumbens. European Journal of Neuroscience 11, 1265-1274.

Damasio, A., 1994. Descartes' Error: Emotion, Reason and the Human Brain. G.P. Putnam, New York.

Damasio, A.R., Tranel, D., Damasio, H., 1990. Individuals with sociopathic behavior caused by frontal damage fail to respond autonomically to social stimuli. Behavioural Brain Research 41, 81-94.

Davis, D.R., Parasuraman, R., 1982. The Psychology of Vigilance. Academic Press, London.

Décary, A., Richer, F., 1995. Response selection deficits in frontal excisions. Neuropsychologia 33, 1243-1253.

Delatour, B., Gisquet-Verrier, P., 2000. Functional role of rat prelimbic-infralimbic cortices in spatial memory: evidence for their involvement in attention and behavioural flexibility. Behavioural Brain Research 109, 113-128.

de Wit, H., Crean, J., Richards, J.B., 2000. Effects of d-amphetamine and ethanol on a measure of behavioral inhibition in humans. Behavioral Neuroscience 114, 830-837.

de Wit, H., Enggasser, J.L., Richards, J.B., 2002. Acute administration of damphetamine decreases impulsivity in healthy volunteers. Neuropsychopharmacology 27, 813-825.

Diamond, A., Briand, L., Fossella, J., Gehlbach, L., 2004. Genetic and neurochemical modulation of prefrontal cognitive functions in children. The American Journal of Psychiatry 161, 125-132.

Diamond, A., Prevor, M., Callender, G., Druin, D.P., 1997. Prefrontal cortex cognitive deficits in children treated early and continuously for PKU. Monographs of the Society for Research in Child Development 62, 1-207.

Dias, R., Aggleton, J.P., 2000. Effects of selective excitotoxic prefrontal lesions on acquisition of nonmatching- and matching-to-place in the T-maze in the rat: differential involvement of the prelimbic-infralimbic and anterior cingulate cortices in providing behavioural flexibility. European Journal of Neuroscience 12, 4457-4466.

Dias, R., Robbins, T.W., Roberts, A.C., 1996. Primate analogue of the Wisconsin Card Sorting Test: effects of excitotoxic lesions of the prefrontal cortex in the marmoset. Behavioral Neuroscience 110, 872-886.

Divac, I., Diemer, N.H., 1980. Prefrontal system in the rat visualized by means of labeled deoxyglucose-further evidence for functional heterogeneity of the neostriatum. The Journal of Comparative Neurology 190, 1-13.

Divac, I., Rosvold, H.E., Szwarcbart, M.K., 1967. Behavioral effects of selective ablation of the caudate nucleus. Journal of Comparative and Physiological Psychology 63, 184-190.

Donoghue, J.P., Herkenham, M., 1986. Neostriatal projections from individual cortical fields conform to histochemically distinct striatal compartments in the rat. Brain Research 365, 397-403.

Downes, J.J., Roberts, A.C., Sahakian, B.J., Evenden, J.L., Morris, R.G., Robbins, T.W., 1989. Impaired extra-dimensional shift performance in medicated and unmedicated Parkinson's disease: evidence for a specific attentional dysfunction. Neuropsychologia 27, 1329-1343. 
Drewe, E.A., 1975. Go-no go learning after frontal lobe lesions in humans. Cortex 11, 8-16.

Dunnett, S.B., 1985. Comparative effects of cholinergic drugs and lesions of nucleus basalis or fimbria-fornix on delayed matching in rats. Psychopharmacology 87, 357-363.

Dunnett, S.B., 1990. Role of prefrontal cortex and striatal output systems in short-term memory deficits associated with ageing, basal forebrain lesions, and cholinergic-rich grafts. Canadian Journal of Psychology 44, 210-232.

Dunnett, S.B., 1993. Operant delayed matching and non-matching to position in rats. In: Sahgal, A. (Ed.), Behavioural Neuroscience: A Practical Approach, vol. 1. University Press, Oxford.

Eagle, D.M., Humby, T., Dunnett, S.B., Robbins, T.W., 1999. Effects of regional striatal lesions on motor, motivational, and executive aspects of progressiveratio performance in rats. Behavioral Neuroscience 113, 718-731.

Eagle, D.M., Robbins, T.W., 2003a. Inhibitory control in rats performing a stopsignal reaction-time task: effects of lesions of the medial striatum and damphetamine. Behavioral Neuroscience 117, 1302-1317.

Eagle, D.M., Robbins, T.W., 2003b. Lesions of the medial prefrontal cortex or nucleus accumbens core do not impair inhibitory control in rats performing a stop-signal reaction time task. Behavioural Brain Research 146, 131-144.

Elliott, R., McKenna, P.J., Robbins, T.W., Sahakian, B.J., 1995. Neuropsychological evidence for frontostriatal dysfunction in schizophrenia. Psychological Medicine 25, 619-630.

Elliott, R., McKenna, P.J., Robbins, T.W., Sahakian, B.J., 1998. Specific neuropsychological deficits in schizophrenic patients with preserved intellectual function. Cognitive Neuropsychiatry 3, 45-70.

Evenden, J.L., 1999. Varieties of impulsivity. Psychopharmacology 146, 348361.

Evenden, J.L., Ryan, C.N., 1996. The pharmacology of impulsive behaviour in rats: the effects of drugs on response choice with varying delays of reinforcement. Psychopharmacology 128, 161-170.

Everitt, B.J., Robbins, T.W., 2000. Second-order schedules of drug reinforcement in rats and monkeys: measurement of reinforcing efficacy and drugseeking behaviour. Psychopharmacology 153, 17-30.

Fletcher, P.J., 1995. Effects of combined or separate 5,7-dihydroxytryptamine lesions of the dorsal and median raphe nuclei on responding maintained by a DRL 20s schedule of food reinforcement. Brain Research 675, 45-54.

Floresco, S.B., Phillips, A.G., 2001. Delay-dependent modulation of memory retrieval by infusion of a dopamine D1 agonist into the rat medial prefrontal cortex. Behavioral Neuroscience 113, 934-939.

Flowers, K.A., Robertson, C., 1985. The effect of Parkinson's disease on the ability to maintain a mental set. Journal of Neurology, Neurosurgery, and Psychiatry 48, 517-529.

Fuster, J.M., 1980. The Prefrontal Cortex. Raven Press, New York.

Gariano, R.F., Groves, P.M., 1988. Burst firing induced in midbrain dopamine neurons by stimulation of the medial prefrontal and anterior cingulate cortices. Brain Research 462, 194-198.

Goldman, P.S., Rosvold, H.E., 1970. Localization of function within the dorsolateral prefrontal cortex of the rhesus monkey. Experimental Neurology 27, 291-304.

Goldman-Rakic, P.S., 1987. Circuitry of primate prefrontal cortex and regulation of behaviour by representational memory. In: Plum, F., Mountacastle, V. (Eds.), Handbook of Physiology: The Nervous System. The American Psychological Society, Bethesda MD, pp. 317-373.

Gotham, A.M., Brown, R.G., Marsden, C.D., 1988. 'Frontal' cognitive function in patients with Parkinson's disease 'on' and 'off' levodopa. Brain 111, 299-321.

Granon, S., Passetti, F., Thomas, K.L., Dalley, J.W., Everitt, B.J., Robbins, T.W., 2000. Enhanced and impaired attentional performance after infusion of D1 dopaminergic receptor agents into rat prefrontal cortex. The Journal of Neuroscience 20, 1208-1215.

Growdon, J.H., Kieburtz, K., McDermott, M.P., Panisset, M., Friedman, J.H., 1998. Levodopa improves motor function without impairing cognition in mild non-demented Parkinson's disease patients. Parkinson Study Group. Neurology 50, 1327-1331.

Haenlein, M., Caul, W.F., 1987. Attention deficit disorder with hyperactivity: a specific hypothesis of reward dysfunction. Journal of the American Academy of Child and Adolescent Psychiatry 26, 356-362.
Harrison, A.A., Everitt, B.J., Robbins, T.W., 1997. Central 5-HT depletion enhances impulsive responding without affecting the accuracy of attentional performance: interactions with dopaminergic mechanisms. Psychopharmacology 133, 329-342.

Harrison, A.A., Everitt, B.J., Robbins, T.W., 1999. Central serotonin depletion impairs both the acquisition and performance of a symmetrically reinforced go/no-go conditional visual discrimination. Behavioural Brain Research 100, 99-112.

Hedreen, J.C., Folstein, S.E., 1995. Early loss of neostriatal striosome neurons in Huntington's disease. Journal of Neuropathology and Experimental Neurology 54, 105-120.

Hermesh, H., Weizman, A., Gur, S., Zalsman, G., Shiloh, R., Zohar, J., GrossIsseroff, R., 2003. Alternation learning in $\mathrm{OCD} /$ schizophrenia patients. European Neuropsychopharmacology 13, 87-91.

Hornykiewicz, O., 1974. The mechanisms of action of L-dopa in Parkinson's disease. Life Science 15, 1249-1259.

Hughes, C., Russell, J., Robbins, T.W., 1994. Evidence for executive dysfunction in autism. Neuropsychologia 32, 477-492.

Humby, T., Laird, F.M., Davies, W., Wilkinson, L.S., 1999. Visuospatial attentional functioning in mice: interactions between cholinergic manipulations and genotype. European Journal of Neuroscience 11, 28132823.

Insel, T.R., Winslow, J.T., 1992. Neurobiology of obsessive compulsive disorder. The Psychiatric Clinics of North America 15, 813-824.

Iversen, S.D., Mishkin, M., 1970. Perseverative interference in monkeys following selective lesions of the inferior prefrontal convexity. Experimental Brain Research 11, 376-386.

Jaskiw, G.E., Karoum, F., Freed, W.J., Phillips, I., Kleinman, J.E., Weinberger, D.R, 1990. Effect of ibotenic acid lesions of the medial prefrontal cortex on amphetamine-induced locomotion and regional brain catecholamine concentrations in the rat. Brain Research 534, 263-272.

Jentsch, J.D., Taylor, J.R., 1999. Impulsivity resulting from frontostriatal dysfunction in drug abuse: implications for the control of behavior by reward-related stimuli. Psychopharmacology 146, 373-390.

Johnson, T.N., Rosvold, H.E., Mishkin, M., 1968. Projections from behaviorally-defined sectors of the prefrontal cortex to the basal ganglia, septum, and diencephalon of the monkey. Experimental Neurology 21, 20-34.

Jones, D.N.C., Barnes, J.C., Kirkby, D.L., Higgins, G.A., 1995. Age-associated impairments in a test of attention: evidence for involvement of cholinergic systems. The Journal of Neuroscience 15, 7282-7292.

Joyce, E.M., Robbins, T.W., 1991. Frontal lobe function in Korsakoff and nonKorsakoff alcoholics: planning and spatial working memory. Neuropsychologia 29, 709-723.

Kelley, A.E., Domesick, V.B., Nauta, W.J., 1982. The amygdalostriatal projection in the rat — an anatomical study by anterograde and retrograde tracing methods. Neuroscience 7, 615-630.

Killcross, S., Coutureau, E., 2003. Coordination of actions and habits in the medial prefrontal cortex of rats. Cerebral Cortex 13, 400-408.

Koskinen, T., Sirvio, J., 2001. Studies on the involvement of the dopaminergic system in the 5-HT2 agonist (DOI)-induced premature responding in a fivechoice serial reaction time task. Brain Research Bulletin 54, 65-75.

Knowlton, B.J., Mangels, J.A., Squire, L.R., 1996. A neostriatal habit learning system in humans. Science 273, 1399-1402.

Kulisevsky, J., Lopez-Villegas, D., Garcia-Sanchez, C., Barbanoj, M., Gironell, A., Pascual-Sedano, B., 1998. A six-month study of pergolide and levodopa in de novo Parkinson's disease patients. Clinical Neuropharmacology 21, $358-362$.

Lange, K.W., Robbins, T.W., Marsden, C.D., James, M., Owen, A.M., Paul, G.M., 1992. L-dopa withdrawal in Parkinson's disease selectively impairs cognitive performance in tests sensitive to frontal lobe dysfunction. Psychopharmacology 107, 394-404.

Lange, K.W., Sahakian, B.J., Quinn, N.P., Marsden, C.D., Robbins, T.W., 1995. Comparison of executive and visuospatial memory function in Huntington's disease and dementia of Alzheimer type matched for degree of dementia. Journal of Neurology, Neurosurgery, and Psychiatry 58, 598-606.

Lapierre, D., Braun, C.M., Hodgins, S., 1995. Ventral frontal deficits in psychopathy: neuropsychological test findings. Neuropsychologia 33, 139-151. 
Lawicka, W., Mishkin, M., Rosvold, H.E., 1975. Dissociation of deficits on auditory tasks following partial prefrontal lesions in monkeys. Acta Neurobiologiae Experimentalis 35, 581-607.

Lawrence, A.D., Hodges, J.R., Rosser, A.E., Kershaw, A., ffrench-Constant, C., Rubinsztein, D.C., Robbins, T.W., Sahakian, B.J., 1998a. Evidence for specific cognitive deficits in preclinical Huntington's disease. Brain 121 , 1329-1341.

Lawrence, A.D., Weeks, R.A., Brooks, D.J., Andrews, T.C., Watkins, L.H., Harding, A.E., Robbins, T.W., Sahakian, B.J., 1998b. The relationship between striatal dopamine receptor binding and cognitive performance in Huntington's disease. Brain 121, 1343-1355.

Lawrence, A.D., Sahakian, B.J., Hodges, J.R., Rosser, A.E., Lange, K.W., Robbins, T.W., 1996. Executive and mnemonic functions in early Huntington's disease. Brain 119, 1633-1645.

Lawrence, A.D., Sahakian, B.J., Rogers, R.D., Hodge, J.R., Robbins, T.W., 1999. Discrimination, reversal, and shift learning in Huntington's disease: mechanisms of impaired response selection. Neuropsychologia 37, 13591374.

Leimkuhler, M.E., Mesulam, M.M., 1985. Reversible go-no go deficits in a case of frontal lobe tumor. Annals of Neurology 18, 617-619.

Liddle, P.F., Friston, K.J., Frith, C.D., Frackowiak, R.S., 1992. Patterns of cerebral blood flow in schizophrenia. The British Journal of Psychiatry 160, 179-186.

Logan, G.D., 1994. On the ability to inhibit thought and action: a users' guide to the stop signal paradigm. In: Dagenbach, D., Carr, T.H. (Eds.), Inhibitory Processes of Attention, Memory and Language. Academic Press, San Diego, pp. 189-239.

Logan, G.D., Schacher, R.J., Tannock, R., 1997. Impulsivity and inhibitory control. Psychological Medicince 8, 60-64.

Lotta, T., Vidgren, J., Tilgmann, C., Ulmanen, I., Melen, K., Julkunen, I., Taskinen, J., 1995. Kinetics of human soluble and membrane-bound catechol $O$-methyltransferase: a revised mechanism and description of the thermolabile variant of the enzyme. Biochemistry 34, 42024210.

Lucey, J.V., Burness, C.E., Costa, D.C., Gacinovic, S., Pilowsky, L.S., Ell, P.J., Marks, I.M., Kerwin, R.W., 1997. Wisconsin Card Sorting Task (WCST) errors and cerebral blood flow in obsessive-compulsive disorder (OCD). The British Journal of Medical Psychology 70, 403-411.

Luciana, M., Sullivan, J., Nelson, C.A., 2001. Associations between phenylalanine-to-tyrosine ratios and performance on tests of neuropsychological function in adolescents treated early and continuously for phenylketonuria. Child Development 72, 1637-1652.

Maruyama, W., Naoi, M., Narabayashi, H., 1996. The metabolism of L-DOPA and L-threo-3,4-dihydroxyphenylserine and their effects on monoamines in the human brain: analysis of the intraventricular fluid from parkinsonian patients. Journal of the Neurological Sciences 139, 141-148.

Malloy, P., Bihrle, A., Duffy, J., Cimino, C., 1993. The orbitomedial frontal syndrome. Archives of Clinical Neuropsychology 8, 185-201.

Manes, F., Sahakian, B., Clark, L., Rogers, R., Antoun, N., Aitken, M., Robbins, T., 2002. Decision-making processes following damage to the prefrontal cortex. Brain 125, 624-639.

Marshall, J.E., Teitelbaum, P., 1977. New considerations in the neuropsychology of motivated behavior. In: Iversen, L.L., Iversen, S.D., Snyder, S.H. (Eds.), Handbook of Psychopharmacology, vol. 7. Plenum, New York, pp. 201-229.

Mavaddat, N., Kirkpatrick, P.J., Rogers, R.D., Sahakian, B.J., 2000. Deficits in decision-making in patients with aneurysms of the anterior communicating artery. Brain 123, 2109-2117.

Mazur, J., 1987. An adjusting procedure for studying delayed reinforcement. In: Commons, M.L., Nevin, J.A., Rachlin, H.C. (Eds.), Quantitative Analysis of Behaviour: The Effect of Delay and Intervening Events on Reinforcement Value. Erlbaum, Hillsdale NJ, pp. 55-73.

McDonald, R.J., White, N.M., 1993. A triple dissociation of memory systems: hippocampus, amygdala, and dorsal striatum. Behavioral Neuroscience 107, 3-22.

McEnaney, K.W., Butter, C.M., 1969. Perseveration of responding and nonresponding in monkeys with orbital frontal ablations. Journal of Comparative and Physiological Psychology 68, 558-561.
McGaughy, J., Dalley, J.W., Morrison, C.H., Everitt, B.J., Robbins, T.W., 2002. Selective behavioral and neurochemical effects of cholinergic lesions produced by intrabasalis infusions of 192 IgG-saporin on attentional performance in a five-choice serial reaction time task. The Journal of Neuroscience 22, 1905-1913.

McGeorge, A.J., Faull, R.L., 1989. The organization of the projection from the cerebral cortex to the striatum in the rat. Neuroscience 29, 503-537.

McLean, A., Dowson, J., Toone, B., Young, S., Bazanis, E., Robbins, T.W., Sahakian, B.J., 2004. Characteristic neurocognitive profile associated with adult attention-deficit/hyperactivity disorder. Psychological Medicine 34, 681-692.

Mehta, M.A., Goodyer, I.M., Sahakian, B.J., 2004a. Methylphenidate improves working memory and set-shifting in $\mathrm{AD} / \mathrm{HD}$ : relationships to baseline memory capacity. Journal of Child Psychology and Psychiatry 45, 293 305.

Mehta, M.A., Manes, F.F., Magnolfi, G., Sahakian, B.J., Robbins, T.W., 2004b. Impaired set-shifting and dissociable effects on tests of spatial working memory following the dopamine $\mathrm{D}(2)$ receptor antagonist sulpiride in human volunteers. Psychopharmacology 176, 331-342.

Mehta, M.A., Sahakian, B.J., McKenna, P.J., Robbins, T.W., 1999. Systemic sulpiride in young adult volunteers simulates the profile of cognitive deficits in Parkinson's disease. Psychopharmacology 146, 162-174.

Mehta, M.A., Swainson, R., Ogilvie, A.D., Sahakian, B.J., Robbins, T.W., 2001. Improved short-term spatial memory but impaired reversal learning following the dopamine $\mathrm{D}(2)$ agonist bromocriptine in human volunteers. Psychopharmacology 159, 10-20.

Meltzer, H.Y., 1989. Clinical studies on the mechanism of action of clozapine: the dopamine-serotonin hypothesis of schizophrenia. Psychopharmacology 99, 18-27.

Middleton, F.A., Strick, P.L., 1996. Basal ganglia and cerebellar output influences non-motor function. Molecular Psychiatry 1, 429-433.

Milner, B., 1963. Effects of different brain lesions on card sorting. Archives of Neurology 9, 100-110.

Mink, J.W., 1996. The basal ganglia: focused selection and inhibition of competing motor programs. Progress in Neurobiology 50, 381-425.

Mishkin, M., Malamut, B., Bachevalier, J., 1984. Memories and habits: two neural systems. In: Lynch, G., McGaugh, J.L., Weinberger, N.M. (Eds.), Neurobiology of Learning and Memory. Guildford, New York, pp. 65-77.

Mobini, S., Body, S., Ho, M.Y., Bradshaw, C.M., Szabadi, E., Deakin, J.F., Anderson, I.M., 2002. Effects of lesions of the orbitofrontal cortex on sensitivity to delayed and probabilistic reinforcement. Psychopharmacology $160,290-298$.

Mobini, S., Chiang, T.J., Al-Ruwaitea, A.S., Ho, M.Y., Bradshaw, C.M., Szabadi, E., 2000. Effects of central 5-hydroxytryptamine depletion on sensitivity to delayed and probabilistic reinforcement. Psychopharmacology $152,390-397$.

Moghaddam, B., Gruen, R.J., Roth, R.H., Bunney, B.S., Adams, R.N., 1990. Effect of L-glutamate on the release of striatal dopamine: in vivo dialysis and electrochemical studies. Brain Research 518, 55-60.

Muir, J.L., Everitt, B.J., Robbins, T.W., 1995. Reversal of visual attentional dysfunction following lesions of the cholinergic basal forebrain by physostigmine and nicotine but not by the 5-HT3 receptor antagonist, ondansetron. Psychopharmacology 118, 82-92.

Muir, J.L., Everitt, B.J., Robbins, T.W., 1996. The cerebral cortex of the rat and visual attentional function: dissociable effects of mediofrontal, cingulate, anterior dorsolateral, and parietal cortex lesions on a five-choice serial reaction time task. Cerebral Cortex 6, 470-481.

Murase, S., Grenhoff, J., Chouvet, G., Gonon, F.G., Svensson, T.H., 1993. Prefrontal cortex regulates burst firing and transmitter release in rat mesolimbic dopamine neurons studied in vivo. Neuroscience Letters $157,53-56$

Murphy, B.L., Arnsten, A.F., Jentsch, J.D., Roth, R.H., 1996. Dopamine and spatial working memory in rats and monkeys: pharmacological reversal of stress-induced impairment. The Journal of Neuroscience 16, 77687775.

Nestor, P.G., O'Donnell, B.F., 1998. The mind adrift: attentional dysregulation in schizophrenia. In: Parasuraman, R. (Ed.), The Attentive Brain. The MIT Press, Cambridg MA, pp. 527-546. 
O’Leary, K.M., Brouwers, P., Gardner, D.L., Cowdry, R.W., 1991. Neuropsychological testing of patients with borderline personality disorder. The American Journal of Psychiatry 148, 106-111.

Olton, D.S., 1982. Spatially organised behaviors of animals: behavioral and neurological studies. In: Potegal, M. (Ed.), Spatial Abilities. Academic Press, New York, pp. 325-360.

Oosterlaan, J., Logan, G.D., Sergeant, J.A., 1998. Response inhibition in AD/ $\mathrm{HD}, \mathrm{CD}$, comorbid $\mathrm{AD} / \mathrm{HD}+\mathrm{CD}$, anxious, and control children: a metaanalysis of studies with the stop task. Journal of Child Psychology and Psychiatry 39, 411-425.

Ornstein, T.J., Iddon, J.L., Baldacchino, A.M., Sahakian, B.J., London, M., Everitt, B.J., Robbins, T.W., 2000. Profiles of cognitive dysfunction in chronic amphetamine and heroin abusers. Neuropsychopharmacology 23, $113-126$.

Orzack, M.H., Kornetsky, C., 1966. Attention dysfunction in chronic schizophrenia. Archives of General Psychiatry 14, 323-326.

Owen, A.M., Downes, J.J., Sahakian, B.J., Polkey, C.E., Robbins, T.W., 1990. Planning and spatial working memory following frontal lobe lesions in man. Neuropsychologia 28, 1021-1034.

Owen, A.M., James, M., Leigh, P.N., Summers, B.A., Marsden, C.D., Quinn, N.P., Lange, K.W., Robbins, T.W., 1992. Fronto-striatal cognitive deficits at different stages of Parkinson's disease. Brain 115, 1727-1751.

Owen, A.M., Morris, R.G., Sahakian, B.J., Polkey, C.E., Robbins, T.W., 1996. Double dissociations of memory and executive functions in working memory tasks following frontal lobe excisions, temporal lobe excisions or amygdalo-hippocampectomy in man. Brain 119, 1597-1615.

Owen, A.M., Roberts, A.C., Hodges, J.R., Summers, B.A., Polkey, C.E., Robbins, T.W., 1993. Contrasting mechanisms of impaired attentional set-shifting in patients with frontal lobe damage or Parkinson's disease. Brain 116, 1159-1175.

Owen, A.M., Roberts, A.C., Polkey, C.E., Sahakian, B.J., Robbins, T.W., 1991. Extra-dimensional versus intra-dimensional set shifting performance following frontal lobe excisions, temporal lobe excisions or amygdalo-hippocampectomy in man. Neuropsychologia 29, 993-1006.

Owen, A.M., Sahakian, B.J., Semple, J., Polkey, C.E., Robbins, T.W., 1995. Visuo-spatial short-term recognition memory and learning after temporal lobe excisions, frontal lobe excisions or amygdalo-hippocampectomy in man. Neuropsychologia 33, 1-24.

Pelham, W.E., Murphy, D.A., 1986. Behavioral and pharmacological treatment of hyperactivity and attention-deficit disorders. In: Herson, M., Bruening, S.E. (Eds.), Pharmacological and Behavioral Treatment: An Integrative Approach. Wiley, New York, pp. 108-147.

Pantelis, C., Barber, F.Z., Barnes, T.R., Nelson, H.E., Owen, A.M., Robbins, T.W, 1999. Comparison of set-shifting ability in patients with chronic schizophrenia and frontal lobe damage. Schizophrenia Research 37, 251-270.

Pantelis, C., Harvey, C.A., Plant, G., Fossey, E., Maruff, P., Stuart, G.W., Brewer, W.J., Nelson, H.E., Robbins, T.W., Barnes, T.R., 2004. Relationship of behavioural and symptomatic syndromes in schizophrenia to spatial working memory and attentional set-shifting ability. Psychological Medicine 34, 693-703.

Parasuraman, R., Davis, D.R., 1977. A taxonomic analysis of vigilance. In: Mackie, R.R. (Ed.), Vigilance, Theory, Operational Performance and Physiological Correlates. Plenum Press, New York.

Park, S.B., Coull, J.T., McShane, R.H., Young, A.H., Sahakian, B.J., Robbins, T.W., Cowen, P.J., 1994. Tryptophan depletion in normal volunteers produces selective impairments in learning and memory. Neuropharmacology 33, 575-588.

Passetti, F., Chudasama, Y., Robbins, T.W., 2002. The frontal cortex of the rat and visual attentional performance: dissociable functions of distinct medial prefrontal subregions. Cerebral Cortex 12, 1254-1268.

Passetti, F., Levita, L., Robbins, T.W., 2003. Sulpiride alleviates the attentional impairments of rats with medial prefrontal cortex lesions. Behavioural Brain Research 138, 59-69.

Passingham, R.E., 1985. Memory of monkeys (Macaca mulatta) with lesions in prefrontal cortex. Behavioral Neuroscience 99, 3-21.

Perry, E.K., Curtis, M., Dick, D.J., Candy, J.M., Atack, J.R., Bloxham, C.A., Blessed, G., Fairbairn, A., Tomlinson, B.E., Perry, R.H., 1985. Cholinergic correlates of cognitive impairment in Parkinson's disease: comparisons with Alzheimer's disease. Journal of Neurology, Neurosurgery, and Psychiatry 48, 413-421.

Petrides, M., 1982. Motor conditional associative-learning after selective prefrontal lesions in the monkey. Behavioural Brain Research 5, 407-413.

Petrides, M., 1986. The effect of periarcuate lesions in the monkey on the performance of symmetrically and asymmetrically reinforced visual and auditory go, no-go tasks. The Journal of Neuroscience 6, 2054-2063.

Petrides, M., 1987. Conditional learning and primate cortex. In: Perceman, E. (Ed.), The Frontal Lobes Revisited. The IRBN Press, New York, pp. 91108.

Petrides, M., Milner, B., 1982. Deficits on subject-ordered tasks after frontaland temporal-lobe lesions in man. Neuropsychologia 20, 249-262.

Posner, M.I., 1980. Orienting of attention. The Quarterly Journal of Experimental Psychology 32, 3-25.

Pribram, K., 1961. A further experimental analysis of the behavioral deficit that follows injury to the primate frontal cortex. Experimental Neurology 3, 432-466.

Pribram, K., Mishkin, M., 1955. Simultaneous and successive visual discrimination by monkeys with inferotemporal lesions. Journal of Comparative and Physiological Psychology 48, 198-202.

Rahman, S., Sahakian, B.J., Hodges, J.R., Rogers, R.D., Robbins, T.W., 1999. Specific cognitive deficits in mild frontal variant frontotemporal dementia. Brain 122, 1469-1493.

Ragozzino, M.E., Detrick, S., Kesner, R.P., 1999. Involvement of the prelimbicinfralimbic areas of the rodent prefrontal cortex in behavioral flexibility for place and response learning. The Journal of Neuroscience 19, 45854594.

Reading, P.J., Dunnett, S.B., Robbins, T.W., 1991. Dissociable roles of the ventral, medial and lateral striatum on the acquisition and performance of a complex visual stimulus-response habit. Behavioural Brain Research 45, $147-161$.

Rieger, M., Gauggel, S., Burmeister, K., 2003. Inhibition of ongoing responses following frontal, nonfrontal, and basal ganglia lesions. Neuropsychology $17,272-282$.

Richards, J.B., Sabol, K.E., de Wit, H., 1999. Effects of methamphetamine on the adjusting amount procedure, a model of impulsive behaviour in rats. Psychopharmacology 146, 432-439.

Robbins, T.W., 1998. Homology in behavioural pharmacology: an approach to animal models of human cognition. Behavioural Pharmacology 9, 509-519.

Robbins, T.W., 2002. The 5-choice serial reaction time task: behavioural pharmacology and functional neurochemistry. Psychopharmacology 163, 362-380.

Robbins, T.W., Everitt, B.J., 1995. Arousal systems and attention. In: Gazzinga, M. (Ed.), The Cognitive Neurosciences. MIT Press, Cambridge MA, pp. 703-725.

Robbins, T.W., Mittleman, G., O’Brien, J., Winn, P., 1990. The neuropsychological significance of stereotypy induced by stimulant drugs. In: Cooper, S., Dourish, C. (Eds.), The Neurobiology of Stereotypy. Clarendon Press, Oxford, pp. 25-63.

Robbins, T.W., Muir, J.L., Killcross, A.S., Pretsell, D., 1993. Methods for assessing attention and stimulus control in the rat. In: Sahgal, A. (Ed.), Behavioural Neuroscience: A Practical Approach, vol. 1. Oxford University Press, New York, pp. 13-47.

Robbins, T.W., Roberts, A.C., Owen, A.M., Sahakian, B.J., Everitt, B.J., Wilkinson, L., Muir, J.L., De Salvia, M., Tovée, M., 1994. Monoaminergic-dependent cognitive functions of the prefrontal cortex in monkey and man. In: Thierry, A.-M., Glowinski, J., Goldman-Rakic, P.S., Christen, Y. (Eds.), Motor and Cognitive Functions of the Prefrontal Cortex. SpringerVerlag, Berlin, pp. 93-111.

Robbins, T.W., Sahakian, B.J., 1979. "Paradoxical” effects of psychomotor stimulant drugs in hyperactive children from the standpoint of behavioural pharmacology. Neuropharmacology 18, 931-950.

Roberts, A.C., De Salvia, M.A., Wilkinson, L.S., Collins, P., Muir, J.L., Everitt, B.J., Robbins, T.W., 1994. 6-Hydroxydopamine lesions of the prefrontal cortex in monkeys enhance performance on an analogue of the Wisconsin Card Sort Test: possible interactions with subcortical dopamine. The Journal of Neuroscience 14, 2531-2544. 
Roberts, A.C., Robbins, T.W., Everitt, B.J., 1988. The effects of intradimensional and extradimensional shifts on visual discrimination learning in humans and non-human primates. Quarterly Journal of Experimental Psychology B 40, 321-341.

Roberts, A.C., Robbins, T.W., Everitt, B.J., Jones, G.H., Sirkia, T.E., Wilkinson, J., Page, K., 1990. The effects of excitotoxic lesions of the basal forebrain on the acquisition, retention and serial reversal of visual discriminations in marmosets. Neuroscience 34, 311-329.

Roberts, A.C., Robbins, T.W., Everitt, B.J., Muir, J.L., 1992. L-dopa withdrawal in Parkinson's disease selectively impairs cognitive performance in tests sensitive to frontal lobe dysfunction. Psychopharmacology 107, 394-404.

Roberts, A.C., Sahakian, B.J., 1993. Comparable tests of cognitive function in monkey and man. In: Sahgal, A. (Ed.), Behavioural Neuroscience: A Practical Approach, vol. 1. Oxford University Press, New York, pp. 165184.

Rogers, R.D., Andrews, T.C., Grasby, P.M., Brooks, D.J., Robbins, T.W., 2000. Contrasting cortical and subcortical activations produced by attentional-set shifting and reversal learning in humans. Journal of Cognitive Neuroscience $12,142-162$.

Rogers, R.D., Baunez, C., Everitt, B.J., Robbins, T.W., 2001. Lesions of the medial and lateral striatum in the rat produce differential deficits in attentional performance. Behavioral Neuroscience 115, 799-811.

Rogers, R.D., Blackshaw, A.J., Middleton, H.C., Matthews, K., Hawtin, K., Crowley, C., Hopwood, A., Wallace, C., Deakin, J.F., Sahakian, B.J., Robbins, T.W., 1999a. Tryptophan depletion impairs stimulus-reward learning while methylphenidate disrupts attentional control in healthy young adults: implications for the monoaminergic basis of impulsive behaviour. Psychopharmacology 146, 482-491.

Rogers, R.D., Owen, A.M., Middleton, H.C., Williams, E.J., Pickard, J.D., Sahakian, B.J., Robbins, T.W., 1999b. Choosing between small, likely rewards and large, unlikely rewards activates inferior and orbital prefrontal cortex. The Journal of Neuroscience 19, 9029-9038.

Rogers, R.D., Everitt, B.J., Baldacchino, A., Blackshaw, A.J., Swainson, R., Wynne, K., Baker, N.B., Hunter, J., Carthy, T., Booker, E., London, M., Deakin, J.F., Sahakian, B.J., Robbins, T.W., 1999c. Dissociable deficits in the decision-making cognition of chronic amphetamine abusers, opiate abusers, patients with focal damage to prefrontal cortex, and tryptophandepleted normal volunteers: evidence for monoaminergic mechanisms. Neuropsychopharmacology 20, 322-339.

Rogers, R.D., Monsell, S., 1995. Costs of a predictable switch between simple cognitive tasks. Journal of Experimental Psychology 124, 207-231.

Rogers, R.D., Robbins, T.W., 2001. Investigating the neurocognitive deficits associated with chronic drug misuse. Current Opinion in Neurobiology 11, 250-257.

Rosvold, H.E., Mirsky, A.F., Sarason, I., Bransome, E.B., Beck, L.H., 1956. A continuous performance test of brain damage. Journal of Consulting Psychology 20, 343-350.

Rosvold, H.E., Szwarcbar, M.K., Mirsky, A.F., Mishkin, M., 1961. The effect of frontal-lobe damage on delayed response performance in chimpanzees. Journal of Comparative and Physiological Psychology 54, 368-374.

Rubia, K., Oosterlaan, J., Sergeant, J.A., Brandeis, D., v Leeuwen, T., 1998 Inhibitory dysfunction in hyperactive boys. Behavioural Brain Research 94, $25-32$.

Rueckert, L., Grafman, J., 1996. Sustained attention deficits in patients with right frontal lesions. Neuropsychologia 34, 953-963.

Saint-Cyr, J.A., Taylor, A.E., Lang, A.E., 1988. Procedural learning and neostriatal dysfunction in man. Brain 111, 941-959.

Sahakian, B.J., Downes, J.J., Eagger, S., Evenden, J.L., Levy, R., Philpot, M.P., Roberts, A.C., Robbins, T.W., 1990. Sparing of attentional relative to mnemonic function in a subgroup of patients with dementia of the Alzheimer type. Neuropsychologia 28, 1197-1213.

Sahakian, B.J., Morris, R.G., Evenden, J.L., Heald, A., Levy, R., Philpot, M., Robbins, T.W., 1988. A comparative study of visuospatial memory and learning in Alzheimer-type dementia and Parkinson's disease. Brain 111, 695-718.

Sahakian, B.J., Owen, A.M., Morant, N.J., Eagger, S.A., Boddington, S., Crayton, L., Crockford, H.A., Crooks, M., Hill, K., Levy, R., 1993. Further analysis of the cognitive effects of tetrahydroaminoacridine (THA) in
Alzheimer's disease: assessment of attentional and mnemonic function using CANTAB. Psychopharmacology 110, 395-401.

Sahgal, A., Lloyd, S., Wray, C.J., et al., 1992. Does visuospatial memory in Alzheimer's disease depend on severity of the disorder? International Journal of Geriatric Psychiatry 7, 427-436.

Sawaguchi, T., Goldman-Rakic, P.S., 1991. D1 dopamine receptors in prefrontal cortex: involvement in working memory. Science 251, 947-950.

Schall, J.D., Stuphorn, V., Brown, J.W., 2002. Monitoring and control of action by the frontal lobes. Neuron 36, 309-322.

Sesack, S.R., Deutch, A.Y., Roth, R.H., Bunney, B.S., 1989. Topographical organization of the efferent projections of the medial prefrontal cortex in the rat: an anterograde tract-tracing study with Phaseolus vulgaris leucoagglutinin. The Journal of Comparative Neurology 290, 213-242.

Setlow, B., Schoenbaum, G., Gallagher, M., 2003. Neural encoding in ventral striatum during olfactory discrimination learning. Neuron 38, 625-636.

Slamecka, N.J., 1968. A methodological analysis of shift paradigms in human discrimination learning. Psychological Bulletin 69, 423-438.

Snyder, H., 1973. Amphetamine psychosis: a "model" schizophrenia mediated by catecholamines. The American Journal of Psychiatry 130, 61-67.

Solanto, M.V., 2001. Attention-deficit/hyperactivity disorder: clinical features. In: Solanto, M.V., Arnsten, A.F.T., Castellanos, F.X. (Eds.), Stimulant Drugs and ADHD: Basic and Clinical Neuroscience. University Press, Oxford, pp. 3-30.

Soubrié, P., 1986. Reconciling the role of central serotonin neurons in human and animal behavior. The Behavioral and Brain Sciences 9, 319-364.

Spinelli, S., Pennanen, L., Dettling, A.C., Feldon, J., Higgins, G.A., Pryce, C.R., 2004. Performance of the marmoset monkey on computerized tasks of attention and working memory. Cogntive Brain Research 19, 123-137.

Stout, J.C., Rodawalt, W.C., Siemers, E.R., 2001. Risky decision making in Huntington's disease. Journal of the International Neuropsychological Society 7, 92-101.

Swainson, R., Hodges, J.R., Galton, C.J., Semple, J., Michael, A., Dunn, B.D., Iddon, J.L., Robbins, T.W., Sahakian, B.J., 2001. Early detection and differential diagnosis of Alzheimer's disease and depression with neuropsychological tasks. Dementia and Geriatric Cognitive Disorders 12, 265-280.

Swainson, R., Rogers, R.D., Sahakian, B.J., Summers, B.A., Polkey, C.E., Robbins, T.W., 2000. Probabilistic learning and reversal deficits in patients with Parkinson's disease or frontal or temporal lobe lesions: possible adverse effects of dopaminergic medication. Neuropsychologia 38, 596-612.

Swedo, S.E., Schapiro, M.B., Grady, C.L., Cheslow, D.L., Leonard, H.L., Kumar, A., Friedland, R., Rapoport, S.I., Rapoport, J.L., 1989. Cerebral glucose metabolism in childhood-onset obsessive-compulsive disorder. Archives of General Psychiatry 46, 518-523.

Taber, M.T., Fibiger, H.C., 1995. Electrical stimulation of the prefrontal cortex increases dopamine release in the nucleus accumbens of the rat: modulation by metabotropic glutamate receptors. The Journal of Neuroscience 15, 3896-3904

Trommer, B.L., Hoeppner, J.A., Zecker, S.G., 1991. The go-no go test in attention deficit disorder is sensitive to methylphenidate. Journal of Child Neurology 6 (Suppl.), 128-131.

Turner, D.C., Clark, L., Dowson, J., Robbins, T.W., Sahakian, B.J., 2004a. Modafinil improves cognition and response inhibition in adult attentiondeficit/hyperactivity disorder. Biological Psychiatry 55, 1031-1040.

Turner, D.C., Clark, L., Pomarol-Clotet, E., McKenna, P., Robbins, T.W., Sahakian, B.J., 2004b. Modafinil improves cognition and attentional set shifting in patients with chronic schizophrenia. Neuropsychopharmacology $29,1363-1373$

Ungerstedt, U., 1971. Striatal dopamine release after amphetamine or nerve degeneration revealed by rotational behaviour. Acta Physiologica Scandinavica. Supplementum 82 (Suppl. 367), 49-68.

Volkow, N.D., Fowler, J.S., 2000. Addiction, a disease of compulsion and drive: involvement of the orbitofrontal cortex. Cerebral Cortex 10, 318-325.

Wade, T.R., de Wit, H., Richards, J.B., 2000. Effects of dopaminergic drugs on delayed reward as a measure of impulsive behavior in rats. Psychopharmacology 150, 90-101.

Ward, N.M., Brown, V.J., 1997. Deficits in response initiation, but not attention, following excitotoxic lesions of posterior parietal cortex in the rat. Brain Research 775, 81-90. 
Watkins, L.H., Rogers, R.D., Lawrence, A.D., Sahakian, B.J., Rosser, A.E., Robbins, T.W., 2000. Impaired planning but intact decision making in early Huntington's disease: implications for specific fronto-striatal pathology. Neuropsychologia 38, 1112-1125.

Watkins, L.H., Sahakian, B.J., Robertson, M.M., Veale, D.M., Rogers, R.D., Pickard, K.M., Aitken, M.R.F., Robbins, T.W., 2005. Executive function in Tourette's Syndrome and obsessive-compulsive disorder. Psychological Medicine 35, 571-582.

Wilkinson, R.T., 1963. Interaction of noise with knowledge of results and sleep deprivation. Journal of Experimental Psychology 66, 332-337.

Weed, M.R., Taffe, M.A., Polis, I., Roberts, A.C., Robbins, T.W., Koob, G.F., Bloom, F.E., Gold, L.H., 1999. Performance norms for a rhesus monkey neuropsychological testing battery: acquisition and long-term performance. Cognitive Brain Research 8, 185-201.

Winstanley, C.A., Chudasama, Y., Dalley, J.W., Theobald, D.E., Glennon, J.C., Robbins, T.W., 2003. Intra-prefrontal 8-OH-DPAT and M100907 improve visuospatial attention and decrease impulsivity on the fivechoice serial reaction time task in rats. Psychopharmacology 167, 304314.
Winstanley, C.A., Dalley, J.W., Theobald, D.E., Robbins, T.W., 2004a. Fractionating impulsivity: contrasting effects of central 5-HT depletion on different measures of impulsive behavior. Neuropsychopharmacology 29, 1331-1343.

Winstanley, C.A., Theobald, D.E., Cardinal, R.N., Robbins, T.W., 2004 b. Contrasting roles of basolateral amygdala and orbitofrontal cortex in impulsive choice. The Journal of Neuroscience 24, 4718-4722.

Wogar, M.A., Bradshaw, C.M., Szabadi, E., 1993. Effect of lesions of the ascending 5-hydroxytryptaminergic pathways on choice between delayed reinforcers. Psychopharmacology 111, 239-243.

Yahr, M., 1990. Principles of medical treatment. In: Stern, G. (Ed.), Parkinson's Disease. Chapman and Hall, London, pp. 496-508.

Zahrt, J., Taylor, J.R., Mathew, R.G., Arnsten, A.F., 1997. Supranormal stimulation of D1 dopamine receptors in the rodent prefrontal cortex impairs spatial working memory performance. The Journal of Neuroscience $17,8528-8535$.

Zohar, J., Judge, R., 1996. Paroxetine versus clomipramine in the treatment of obsessive-compulsive disorder. OCD Paroxetine Study Investigators. The British Journal of Psychiatry 169, 468-474. 